\title{
Interférences
}

Ars scribendi

$6 \mid 2012$

La question de la littérarité

\section{Considérations sur la facture spécifique des poèmes catulliens}

\section{Mihaïl Nasta}

\section{(2) OpenEdition}

1 Journals

Édition électronique

URL : http://journals.openedition.org/interferences/190

DOI : 10.4000/interferences. 190

ISSN : $1777-5485$

Éditeur

HiSoMA - Histoire et sources des Mondes antiques

Édition imprimée

Date de publication : 1 janvier 2012

ISSN : 1777-5485

Référence électronique

Mihaill Nasta, "Considérations sur la facture spécifique des poèmes catulliens », Interférences [En ligne], 6 | 2012, mis en ligne le 11 décembre 2014, consulté le 15 septembre 2020. URL : http:// journals.openedition.org/interferences/190; DOI : https://doi.org/10.4000/interferences.190

Ce document a été généré automatiquement le 15 septembre 2020.

Tous droits réservés 


\title{
Considérations sur la facture spécifique des poèmes catulliens
}

\author{
Mihaïl Nasta
}

\section{Éléments du contexte historique}

1 Ayant sous les yeux une première ébauche du projet « Avènement et reconnaissance de la littérarité ", il m'est venu à l'esprit de refaire brièvement une mise au point des problèmes qui ont trait à l'énonciation des thèmes et aux enjeux de l'expression littéraire chez Catulle, à l'époque d'un premier classicisme ('romain'), lorsque les modèles grecs sont parfois transposés presque littéralement, même si la facture du kata lepton coexiste avec l'emprise d'une sincérité qui répercute des tonalités 'vulgaires' et très 'physiques' (surtout quand il s'agit de sexualité), comme si le tempérament mis à l'épreuve devait s'affirmer dans un élan provocateur, associé à la rudesse et à l'authenticité des Romulidae. Je retrouve dans la démarche catullienne la séparation et la convergence de ces deux tracés alternatifs. D'une part, on assiste au déploiement des procédés spécifiques pour les poetae noui, artisans prolixes; d'autre part, l'ego du poète se manifeste avec une spontanéité troublante ${ }^{1}$.

2 Dans cet ordre d'idées, dès qu'on élargit le tour d'horizon, afin de caractériser l'emprise des modes littéraires et les prototypes qui avaient eu la faveur du public à l'époque de la République, on s'aperçoit que le traitement de l'intrigue chez les anciens auteurs de comédies privilégiait les thèmes grecs, alors que dans ce même espace des manifestations culturelles la tenue de l'épopée imposait aux poètes une thématique inspirée du passé romain. Les performances des genres typiques d'un patrimoine traditionnel donnaient accès au spectacle vivace des mœurs, reflets de l'actualité, ravivés par les sermones sur l'écran de la satura, véritable production locale du terroir italique. Néanmoins, au niveau des relations interhumaines, malgré des accrocs de toutes sortes, dans la Rome républicaine on verra déjà s'imposer une acculturation subreptice des valeurs helléniques ou 'orientales' (lato sensu) ${ }^{2}$. La plupart du temps, avant l'époque de la dynastie des Césars, il semblerait que les intellectuels grecs 
œuvrant dans les milieux traditionnels romains ne jouissaient pas des prérogatives du ciuis Romanus optimo iure. À maintes reprises on les traitait de graeculi ou de raisonneurs suspects, comme c'est le cas pour les groupements (ou 'sectes') de philosophes. Et je songe notamment aux pythagoriciens - et à d'autres encore - harcelés du temps de Sylla. Pourtant, certaines familles aristocratiques férues de 'belles lettres' accueillaient des grammairiens et des poètes, comme l'avaient fait les Scipions et surtout le cercle de Lucius Calpurnius Piso. Témoignages d'une époque de transition, les papyrus retrouvés dans la Villa Pisonum attestent le rayonnement du poète grammairien Philodème, propagateur de l'épicurisme. Et la fréquentation des auteurs grecs portait ses fruits, comme le montre sur le plan formel la variété des emprunts, les thèmes et l'inspiration que les poètes latins puisaient dans le vivier inégalable des épigrammes grecques, sans oublier leur allégeance multiple aux Muses Siciliennes des idylles ${ }^{3}$, aux succédanés de l' epyllion alexandrin et aux genres qui prenaient la relève d'un savoir spécialisé (astronomie, descriptions - ou ekphrasis - des plantes, des mirabilia, des monuments et des coutumes). Un modèle de perfection qui apparente les poetae noui aux prédécesseurs alexandrins du 'néotérisme' leur était fourni par 'l'école' de Callimaque. Ils en adaptent les paradigmes du travail d'orfèvre, de même qu'ils se proclament disciples d'Euphorion ou émulateurs de Théocrite et des auteurs de diatribes ${ }^{4}$. On touche ainsi aux points névralgiques des influences croisées. D'un côté, la poésie tend à se distancer des Anciens et les versificateurs traitent avec un certain mépris la lourdeur d'Ennius ou les redites de Lucilius : une fronde qui particularise les options stylistiques des poètes juvéniles - dont Valerius Cato et surtout Licinius Calvus, Caecilius, Helvius Cinna, Cornificius -, tous mentionnés (sinon chéris) par Catulle, car ils se targuent de rivaliser avec l'artisanat concis et le style châtié (lepos) de Callimaque ${ }^{5}$. D'un autre côté, il y a la tendance à transposer des mœurs romaines, avec des tournures dont les plus fascinantes s'apparentaient chez Catulle soit aux invectives des soudards, soit aux formules d'envoûtement et aux chants - suaves ou primesautiers - des coutumes anciennes, qui ravivaient la scénographie d'un rite nuptial. Tout ceci compte beaucoup, dès qu'on s'efforce de caractériser une 'ambiance d'auteur': les tournures très personnelles du lepidus nouus libellus.

\section{Discerner les factures}

Pour une approche de la sociologie littéraire ces 'discriminations' ont leur poids, car les historiens littéraires procèdent parfois comme des arpenteurs qui pratiqueraient des lotissements. Certainement, ils nous montrent que les poetae noui sont tous devenus de fervents adeptes du raffinement alexandrin, mais l'analyse des factures oublie parfois de s'attarder sur les options déroutantes de ces mêmes artistes, qui n'avaient pas renié le filon de la satura (malgré leur coquetterie de cantores Euphorionis) ${ }^{6}$, toujours d'attaque, tout aussi capables de pratiquer l'invective ou de jouer avec les mots, quand ils dénigraient ou donnaient le change aux rhéteurs sans épargner les politiciens qui cherchaient leur avenir dans des expéditions guerrières, aux confins des provinces romaines - l'exemple de Memmius, haut fonctionnaire lettré, taquinant lui-même la Muse à ses heures, ne serait qu'une exception qui confirme la règle. D'où aussi l'épandage des violences verbales, qui s'accumulent chez Catulle, avant de culminer comme un point d'orgue, dans la formule opprobria Romuli Remique, pour brosser un tableau de mœurs, destiné à mettre en garde ses compagnons fourvoyés (Catul. 28, 15). Signalons également dans les textes catulliens bon nombre de références pittoresques 
aux personnages du 'milieu', en alternance avec les sautes d'humeur de l'auto-invective (sans oublier la dialectique du «moi» et de "l'autre», marquée par le dépit). On s'aperçoit que les convenances du style - y compris la censura ueterum des auteurs classiques - n'étaient pas encore de mise... Il faudrait aussi se positionner par rapport à Paul Veyne ${ }^{7}$, pour dissocier la 'mouvance catullienne' des autres sédiments classiques, lors du recentrage qui s'imposera à distance d'une génération chez les élégiaques du règne d'Auguste (un quatrième niveau du processus mimétique). Parmi les ouvertures symptomatiques du monde littéraire, une autre série de propos met en scène l'échange de poésies manuscrites ou de libelli, qui accompagnent cadeaux ou épanchements divers à l'heure des rencontres galantes (autant de facettes du propemptikon). Depuis les dernières décennies de la République, on s'activait 'à faire des livres avec des livres', par le truchement des œuvres qui étaient souvent accréditées< > diffusées, à l'occasion des lectures à haute voix ${ }^{8}$.

4 Sans doute, il faut bien soupeser des jugements plus nuancés sur la stratégie des genres et des colores rhetorici, une fois qu'on aura constaté que le 'travail de la lime' chez Catulle, Calvus, Cinna (et alii) implique non seulement une volonté de clôture dans le domaine de l'ars, mais en même temps des zones d'ombre, assorties de quelques disparités frappantes. En premier lieu, dès le $\mathrm{II}^{\mathrm{e}}$ siècle av. J.-C. on voit se manifester certaines disparités de la réception, la prose des orateurs ayant déjà atteint des sommets, alors que les poètes romains novateurs peinaient à trouver les faveurs d'un public plus large (toujours enclin à goûter la verve des satires de Lucilius ou à 'subir' l'emprise du style spécifique, «typé », des genres traditionnels dramatiques : la palliata vs la togata). Plus tard, un Horace, dans ses épîtres littéraires, critiquera fermement les préjugés tenaces d'un public aux options conservatrices, qui persistait à favoriser l'archaïsme, tandis que les imitateurs des poètes plus récents - 'modernes', par rapport à Naevius et à la Loi des Douze Tables! - ne faisaient que singer les performances de quelques auteurs grecs favoris. De ce décalage, qui se fait jour dans la dynamique des genres littéraires, témoignent aussi les jugements de Cicéron, adepte surdoué d'un 'atticisme' tempéré, plus cohérent que d'autres dans ses options stylistiques. Or il méprisait le maniérisme, tout comme les 'cachotteries' des poetae noui. En fait, Cicéron l'uomo universale - avait eu la révélation de Lucrèce, auteur dont il s'avérait incapable de suivre le sillage 9 . Ailleurs, les faits glorieux de son consulat sont advenus à temps pour dicter au "sauveur de la patrie » les vers d'une célébration vaine de sa propre personne... Par contre, il n'y a pas trace d'un enkomion littéral de soi-même chez Catulle, alors qu'un éloge ironique de Marcus Tullius joue sur les hyperboles dans le carmen 49, pour monter en épingle «l'excellence » de cet avocat (mention parallèle du patronus, en fin de vers, clôturant le poème).

\section{Aux abords de l'extrême}

5 Celui qui s'accoutume à recenser de pareilles anfractuosités du terrain littéraire devra finalement se rendre à l'évidence. Il s'agit d'établir un bilan comparatif des remous qui avaient changé la donne - entre 120 av. J.-C. et les années 15-20 apr. J.-C. -, à l'époque d'une recherche normative des formules et des 'factures stylistiques' différenciées, dont la gradation et les performances oratoires avaient façonné la physionomie de l' elocutio sur le plan du sermo urbanus - chez les prosateurs exemplaires (notamment chez Hortensius et Cicéron, Salluste et César ${ }^{10}$, vrais prototypes du langage classique). 
Ailleurs, dans le domaine de la poésie, on assistait aux poussées du maniérisme, qui interféraient avec des 'écarts' de l'écriture: élancements lyriques, à côté des vulgarismes, inserts du parler quotidien, tournures quasi folkloriques, prédilection pour certains néologismes, qualifiant des modes vestimentaires ou l'importation des objets exotiques de consommation (telle cette mention fréquente des parfums, qui attisent l'érotisme au banquet), évocation des plaisirs épicés, à côté des hapax legomena et de certains décalques, visant à 'mimétiser' les Alexandrins d'une façon plus subtile. Autant de phénomènes significatifs, souvent très intéressants, car les mêmes auteurs romains s'avèrent des artisans impeccables, quand ils ne sont pas maniéristes et/ou 'pervertis'. Les meilleurs poètes savaient déjà susciter 'l'imprévu' dans leurs callidae iuncturae, à partir d'un aprosdoketon, et ils se plaisaient à manier des pointes (à l'égal des agudezas de l'invention poétique), en alternance avec les sinuosités de la mythologie descriptive, réinventée, comme ces étonnants décalques qui s'entrelacent pour imiter Callimaque dans la Boucle de Bérénice* (Catul. 66) ou - dans un autre contexte l'imagerie marine qui tresse un prélude aux Noces de Thétis et Pélée (Catul. 64, 1-21). Làbas, dès l'ouverture, un effet de surprise jaillit de la vague, lorsque des Nymphes (à l'instar des Néréides ?) montrent leurs tétons aux Argonautes (Catul. 64, 16-18). Le texte se 'déboîte' dans l'épanouissement de ces descriptions narratives, comme un écrin à merveilles. Par contre, un aspect ingrat du dénigrement se manifeste aux heures sombres... Ces contrastes réfractent, semble-t-il, les oscillations périodiques d'un tempérament d'artiste, son imaginaire qui fonctionne en deux temps. Les fascinants récits à volutes descriptives (ekphraseis) proviennent d'une avant-scène occultée par les travers d'une vie amoureuse livrée aux hantises, traversée par les alternances de la passion déçue ou trahie, capable subitement de surmonter son déchirement. Cadences binaires : un sursaut de lucidité succède aux avancées de la rêverie et aux ébats d'une sexualité androgyne. Le dialogue de Catulle avec son genius (ou daimôn) déclenche les symptômes d'un épisodique dédoublement ${ }^{11}$. Pourtant, il ne surgit pas comme un pâle contretype de l'ego, linéaments de l'Autre, persona qui trouble vers midi le miroir de l'onde, mirage du Narcisse. Aux abords de l'extase ('petite mort' du spasme ou palpitation érotique), celui qui était mené se ressaisit avec lucidité : un alter ego de l'amant se réveille, capable de "s'endurcir ", dans un dialogue à trois. Les itérations du carmen 8 sont des relances, depuis le présent, à travers des souvenirs obsédants qui ne cessaient de l'acheminer sur une voie de perdition, et les vocables encadrés /perisseperditum/ évoquent un passé dont il faut exorciser les écueils, renverser la cadence (Catul. 8, 1-5) :
Miser Catulle, desinas ineptire,
Et quod uides perisse perditum ducas,
Fulsere quondam candidi tibi soles,
Cum uentitabas quo puella ducebat
Amata nobis quantum amabitur nulla ${ }^{12}$.

6 Les répétitions disjonctives exhortent la conscience à transformer le 'non-vouloir' en refus. Une triple semonce referme le carcan (Catul. 8, 11-18) :

$$
<. . .>
$$

Sed obstinata mente perfer obdura, Vale, puella. Iam Catullus obdurat, Nec te requiret nec rogabit inuitam; At tu dolebis, cum rogaberis nulla. $<. . .>$

Quem nunc amabis ? cuius esse diceris? [couplage rimé et polyptoton] 
Quem basiabis? cui labella mordebis?

At tu, Catulle, destinatus obdura.

7 Plus tard, on aboutit encore au non-retour, dans le carmen 58, où la complainte ramène au premier plan le portrait infamant de Lesbie Clodia, une aristocrate avilie parmi les malfrats qu'elle a débauchés aux carrefours des ruelles. La réitération à distance du thème obsédant amorcé auparavant renforce maintenant les accents inimitables du pathétique, aux abords des reniements dont témoigne la ritournelle (voir supra Catul. 8, 5), qui flétrit une sombre déchéance obscène (Catul. 58) :

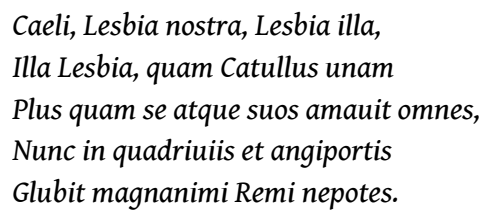

Par contraste, les mouvements alternatifs de la conscience rejoignent l'interface des constructions verbales dans un epyllion où de vastes plans aux éclaircies merveilleuses ravivent la muthopoiésis, comme ces figures du drapement qui raconte l'histoire d'Ariane, à l'occasion des noces de Thétis et Pélée (Catul. 64, 50 sq. : le topos de la toile historiée). On se repose dans une clairière du récit, mais le psychodrame se profile, au rivage gnosien abrupt, quand la fille de Minos, " aux yeux tristes, semblable à la statue d'une bacchante pétrifiée » (ibid., v.60-62), suit du regard le navire de Thésée qui s'enfuit. Là encore - quoique autrement, par saccades -, il s'agit de soubresauts de lucidité, après la torpeur d'une hypnose maléfique dans les dunes (v.34-35: Vt pote fallaci... excita somno/ desertam in sola se certat harena). Ariane ayant compris avec horreur le perfide stratagème de son amant, la voix du narrateur accompagne son désarroi (v. 73-74: illa uicem curans toto ex te pectore, Theseu, <...> tota pendebat perdita mente). Le monologue de la jeune fille subitement révoltée se termine par l'intervention tout aussi brusque de Iacchus (Dionysos), 'enflammé d'amour', dieu providentiel qui enlève Ariane parmi les étoiles (virage fatidique, pure extase céleste). Après l'enclave du mythopoème d'Ariane, inséré ad incastro (v. 50-264 !), le récit d'encadrement pourra désormais continuer et dans une perspective plus ample nous saisissons les constantes d'une procédure typique de l'agencement verbal et conceptuel. La maîtrise catullienne a perfectionné les procédés de l'inclusion discursive avec des relances périodiques, des itérations et des contrastes, nettement articulés dans le tissu verbal (métricoprosodique), raccordé aux inflexions du sens (idéation des poèmes). Paul Claes a forgé un appellatif spécialement réservé à cette démarche stylistique du poète : concatenatio Catulliana $^{13}$. Pour ma part, je voudrais préciser les attaches d'un langage analogique instancié, qui infléchit le débit du texte au niveau de l'idéation : symétries inclusives et ruptures de la phrase, récurrence des notions et contrastes, surfilage ou 'enchaînement' (concatenatio) des figurae sententiarum. Le contour des éléments similaires ou récurrents se précise à l'intérieur d'un schème suprasegmental qui ferme la figure du poème, comme la jointure d'un cadre. Dans quelques réalisations extrêmes, on pourrait se référer au jeu verbal des énigmes, apparenté aux variantes de l'oxymore et du polyptoton, largement utilisés depuis la Renaissance italienne. Une récurrence phrastique des éléments du discours produit son effet de 'pointe' et valorise le sens d'un élément central enchâssé : mot-appellatif, locution ou thème substantivé. Cela correspond aux tournures que l'on pourrait qualifier de figures ad incastro (selon une terminologie italienne du langage encodé) ${ }^{14}$. Le même type de figure devient plus accessible quand la textualité s'organise au moyen d'une structure circulaire 
d'enchaînement, connue sous le nom de Ringkomposition ("composition sous forme d'anneau »). De tels effets prolifèrent non seulement à l'intérieur d'un poème mais surtout d'un carmen à l'autre (corrélats thématiques significatifs). Les factures itératives de la Ringkomposition abondent partout dans le recueil catullien, associées aux diffractions d'une polyphonie alerte, qui relance des mots, amplifie leur écho dans un vers entier légèrement modifié, revient aux tonalités du début par une dernière épanalepse qui enfonce le clou! Telle amorce d'éloge de Catul.24 devient un avertissement :

O qui flosculus es Iunentiorum [en assonance avec non horum modo du vers 2] $<. . .>$

mallem diuitias Midae dedisses [ $\mathrm{d}$ allitérant !]

isti cui neque seruus est nec arca,

quam sic te sineres ab illo amari.

"Qui ? non est homo bellus? » inquies. - Est. [Enclave d'une focalisation minimale]

Sed bello huic neque seruus est nec arca.

Hoc tu quam lubet abice eleuaque ;

Nec seruum tamen ille habet neque arcam.

La triple récurrence des termes d'enchâssement s'efforce d'ébranler toutes les tentatives du candide Juventius de fréquenter un rival méprisable. Le jeune homme doit se rendre compte du manque à gagner dans son égarement dangereux; il se débat, encastré lui-même au beau milieu de cette ironique révélation : nec seruum habet neque arcam... Une ample recherche de Dettmer analyse neuf cycles de poèmes ${ }^{15}$, reliés par des anneaux de correspondances dans tout le recueil (comme les miniatures du Passer, couplées avec la complainte de Catul. 3 et les pièces $4-14$ ou le cycle $45-60$, axé sur l'évocation douce-amère des attentes amoureuses et des paysages contrastés). Il faudrait encore insister sur la texture des nombreuses 'parties' modulables, imitant une cantilène, même quand il est question de poésies qui sont destinées à circuler sous forme de livres ou de pamphlets (libelli, volumina, pugillaria, codicilli), transcrits à partir des tablettes. Les charges, la description limpide, les surprises du quotidien imagé, la pantomime du sexe ou des manœuvres érotiques alternent avec la véhémence du désir sur le terrain de l'expérimentation littéraire objectivée.

Le cycle des baisers gravitera, lumineux, hors du temps, autour d'un vrai pôle des amours, qui aurait apporté la plénitude, le rayonnement du vrai désir comblé, si Lesbie de tout son être pouvait acquiescer... De là ces accents de ferveur dans l'immédiat (Catul. 5 et sa réplique d'enchaînement, Catul. 7) et l'hyperbole des mille étreintes qui mettraient les amants à l'abri des jalousies (phthonos/inuidia), du fascinus («mauvais œil »), au dam des vieux médisants (Catul. 5) :

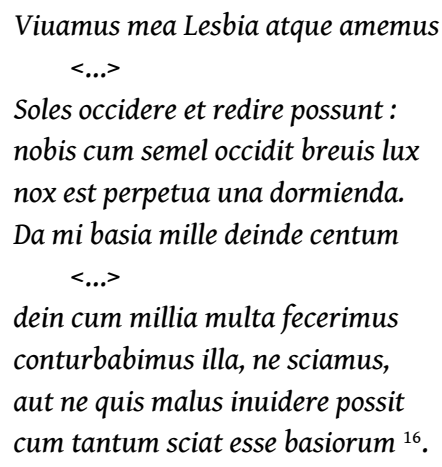


11 Après une invitation indiscrète (Catul. 6) à porter jusqu'aux nues (lepido uocare uersu) les amours d'un ami qui les cache, viendra le pendant du premier appel inassouvi, qui referme le cercle des baisers à Lesbie (Catul. 7) :

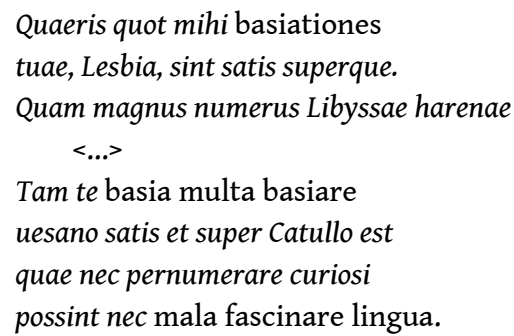

Dans un élan polémique (Catul. 16), Catulle s'attaque à ses détracteurs, qui n'arrivent pas à comprendre que le poète versificateur doit rester dans ses intentions « chaste et pieux » (castum esse decet pium poetam), alors que ses vers auront du sel et de la grâce seulement s'ils peuvent ondoyer, "sensuels et plutôt dévergondés ", pour exciter le prurit, non pas chez les enfants, mais pour les « poilus aux reins engourdis ». Quant aux «mille baisers» (millia multa basiorum) qu'il donne à lire dans ses poèmes, ils ne démarquent pas son manque de virilité, bien au contraire... On voit bien que le «baiser» devient l'emblème d'une extase amoureuse ou d'une tendre amitié (comme en Catul. 9: "baiser les yeux et le joyeux visage " de l'ami Veranius à son retour). Effusions que les rustres calomniateurs ne sont pas dignes d'accueillir. Ils seront stigmatisés par une formule obscène, qui enchâsse le poème (Catul.16, 1 et 14), à l'instar de quelque tabella (terme utilisé chez lui ailleurs), où s'inscrit la menace diffamante: Pedicabo ego uos et irrumabo! Par contre, des effusions sincèrement délicates s'accompagnent de basia, du basiare, d'une "moisson de baisers » (seges osculationis, Catul. 48), du tendre sauiolum et du piège des «baisers volés" (Catul. 99). Mais sur le versant de la diffamation, l'amour cupide ne sera pas épargné. Dans la série des invectives catulliennes «haineuses» (Catul.41), une malheureuse amante de Mamurra devient la catin qui fait des siennes, réprouvée. Lamentable déconfiture d'une simple prostituée :

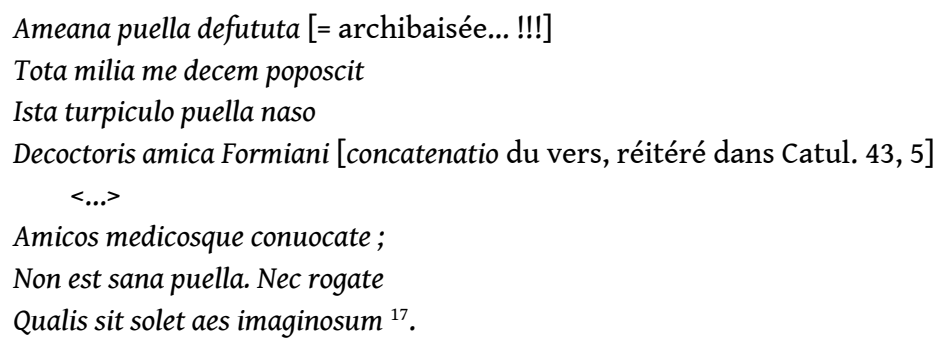

13 Les imprécations donnent ici une image très peu flatteuse des "galéjades » qu'on se racontait parmi les jeunes camarades du poète véronais! Le seul défaut honni de la misérable catin Ameana était d'avoir demandé une taxe trop élevée pour ses prestations : Tota millia me decem poposcit. Et le carmen traite à cette occasion avec un mépris souverain les feintes et les déboires de l'amour vénal (Vénus pandemia qui joue avec ses aficionados...).

Parmi tous les symptômes d'un brassage des styles variés, chez d'autres néotériques les déploiements artificiels n'étaient pas encore les vecteurs d'une transformation effective des normes, comme celle qui amènera l'instauration d'un équilibre classique ${ }^{18}$. D'où aussi les critiques et la caricature des méchants poètes, prolixes à souhait. Elles mettent à mal Suffenus (et compagnie), éditeur très soigné, prétentieux, de «livres 
neufs, aux ombilics neufs» (Catul.22), cible des pirouettes, de l'antiphrase et des ironies en cascade.

\section{Cerner une approche méthodique}

Même s'ils acceptent de modifier par endroits les approches d'une lecture continue, qui retracerait les soubresauts déconcertants du parcours biographique, la plupart des interprètes continuent à revisiter l'œuvre catullienne dans l'ordre des 116 carmina, transmis par le principal manuscrit (descendant du Codex Veronensis perdu). Des correspondances frappantes, un lacis de répétitions, des attaches de la discursivité nous interpellent à travers les méandres d'une trajectoire lyrique. Néanmoins, il est souvent malaisé d'obtenir une synthèse cohérente des jugements critiques. Doit-on parcourir la séquence des aveux et la réunion des pièces aux arguments divers comme on examine le réseau d'une documentation polyphonique, transcrite ou publiée dans un certain désordre, qui nous a préservé un projet d'auteur? Selon des philologues minutieux, aux présupposés rigides, certains rapiéçages des tracés discontinus plaideraient pour un travail d'agencement, confié à 'l'éditeur' (selon certains, Nepos lui-même!) ou au librarius (avatar d'un secrétaire). Quoi qu'il en soit, le souci de coarticuler les éléments d'un recueil hétérogène de poésies a imposé les critères d'assemblage qui correspondent finalement à la distribution des structures métriques :

- I. Les relais des polymetra conventionnels stylisés sont agencés dans la première section (Catul.1-61), celle qui ressemblerait le mieux au libellus d'origine. Le carmen 61 est un epithalamion ${ }^{19}$, pièce lyrique aux vers brefs, dont les strophes ont un contour apparenté à celui d'autres polymetra (Catul. 34).

- II. Une deuxième section regroupe les 'strophes' d'un Hyménée aux vers longs (Catul. 62, versifié en hexamètres dactyliques), suivi des amples galliambes de Catul. 63 et de l'epyllion Catul. 64 (hexamètres dactyliques), structures homogènes de la plus longue poésie du corpus (407 vers).

- III. Une tendance à normaliser les profils de la versification se fait jour dans la troisième section, réservée uniquement au distique élégiaque (Catul. 65-116).

Prenant appui sur les vestiges assez peu clairs d'une partition repérée dans quelques témoignages de la tradition manuscrite, certains philologues n'hésitent pas à parler de trois (ou quatre) 'volumes' distincts de la poésie catullienne. Comme on le verra, nous accordons notre préférence à l'hypothèse d'un projet à trois volets, conçu et réalisé par le poète lui-même, séduit par l'ordonnance des genres discursifs (schémata lexeôs et charaktêres poḯmatôn). Néanmoins, il ne parvint jamais à parachever l'ouvrage de son vivant et ce furent des amis lettrés ou des grammairiens qui entreprirent un dernier travail de finition à l'intérieur des sections, afin d'équilibrer l'envergure du volumen ${ }^{20}$. Quant à la modulation des contenus, l'assemblage dominé par un principe ordonnateur "décalé » n'a pas modifié la physionomie d'ensemble du recueil, qui reflète les tiraillements de l'énonciateur: sous les apparences d'un tracé chaotique ${ }^{21}$, des images parfaitement découpées se succèdent sur l'écran de l'évocation. Le tissage des pièces de dimensions inégales dans les sections I (Catul. 1-61) et III (Catul. 65-116) encadrera le groupe des poésies à programme de la section centrale, II (Catul. 62-64), diffraction thématique des compositions à vers longs. Pour m'en tenir aux positions les plus raisonnables, je tenterai d'éviter les conjectures hasardeuses des spécialistes qui ont élaboré la théorie d'une restructuration totale, imposée a posteriori au recueil. De tels 
présupposés méthodiques sont étayés par un parti-pris organiciste. Il est préférable de ne pas négliger les indices d'un arrière-plan génétique (l'éclosion mouvementée des textes). Des repérages plus équilibrés dans le périmètre du recueil nous orientent sur les pistes d'un constat différencié, qui ne perd pas de vue la triple disposition des poèmes.

\section{Le statut des polymetra et la tripartition du corpus}

Dès les premiers accords (Catul.1, 1-2), la dédicace prend son élan à partir d'une interrogation gracieuse. À qui « faire le don » du libellus, châtié, empreint de nouveauté, bien ficelé, comme un rouleau aux marges polies à la pierre ponce rêche? Sans doute à Nepos, auteur 'savant et laborieux', qui a su néanmoins apprécier les nugae de son ami... L'imagerie symbolisante (v. 3-7) devrait se rapporter d'une manière ou d'une autre au support dénotatif de l'opus absolutum. Ce qui n'a jamais signifié qu'on puisse atteindre l'état inertiel d'un ouvrage 'parachevé', comme l'assemblage d'une maison ou la maîtrise de tout autre artefact, érigé en trois dimensions. Tout au plus, on reconnaît dans ces vers une formule de lancement à litotes: simple préfiguration du recueil 'abouti', qui se présenterait chez Horace (Ars 23) porté à son terme, simplex et unum. D'une manière ambivalente, «tout» ce qui se trouvera dans ce 'joli petit livre' - son contenu «tel qu'il est » - appartiendra à Nepos ${ }^{22}$. Ainsi, le texte inaugural pose comme principe suprême l'exigence de la poikilia : une 'variation' constante des factures et des thèmes qui devait assurer la pérennité du livre. L'examen des factures métriques nous permet de vérifier la réalisation de ce programme dans la première partie du volumenrouleau (Catul.1-61), qui pouvait parfaitement se suffire à elle-même et frayer son chemin comme un libellus, ainsi que l'ont qualifiée souvent la plupart des critiques, lorsqu'ils mentionnaient un recueil catullien des polymetra (du premier 'volet'). Sur un total de 11 schémas de la versification ('patrons' métriques modélisés ou patterns), cette première section utilise 8 modèles (ou schémas) différents (répartis de manière quasi aléatoire), avec leurs propres découpages (soit des strophes, soit des arrimages kata stichon), dont 4 proviennent d'une refonte hellénistique des modules anciens, transmis par les poètes lyriques du monde grec (vers 'éoliens' de Sappho, parties chorales de la dramaturgie, chants ou mélè traditionnels). Chaque fois, le poète véronais a su maîtriser avec brio des formes adaptées à partir d'un patrimoine traditionnel de la versification.

Voici maintenant le tableau des factures métriques utilisées dans la première section (celles d'un corpus auquel on a pu appliquer stricto sensu le titre générique de Polymetra).

19 - L'emploi de l'hendécasyllabe phalécien (vers de 11 syllabes, issu de l'expansion d'une matrice adonienne ou choriambique) prédomine largement, dès le poème-dédicace. On notera sur le plan des concordances métrico-syntaxiques l'enclavement d'un mot hautement significatif, soit après le noyau choriambique de chaque vers, soit après le dactyle, toujours en position de diérèse (pour certains métriciens 'après une coupe principale') :

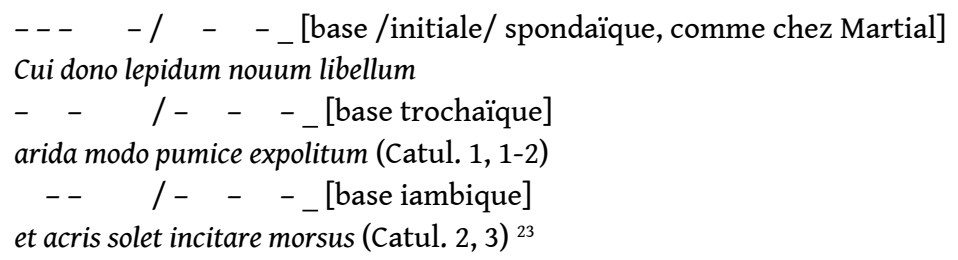


Plus de 70 vers en hendécasyllabes phaléciens commencent soit par un trochée, soit par un iambe. Dans Catul. 55 et 58b, le second pied est parfois un spondée. En pourcentage : 40 sur l'ensemble des 61 poèmes appartenant au genre des polymetra présentent une configuration de ce type. Alors qu'ils sont à l'origine teintés de mélismes lyriques, notre poète diversifie leur usage, pour en faire souvent des armes de l'invective et, dans cette acception, hendecasyllabi devient le synonyme des charges satyriques - cf. Catul. 12, 10 (menace des hendecasyllabos trecentos!); de même Catul. 4 et 43, etc., à l'égal des iambi, perçus comme des invectives agressives (truces uibrare iambos, dans 36,5 , pièce versifiée en hendécasyllabes phaléciens!) ${ }^{24}$. Ailleurs, des pièces qui ont ce même patron métrique (hendécasyllabes phaléciens) sont des appels tendres (Catul. 3 et 7), des cantilènes (Catul.6, 7), des tableaux de genre aux évocations descriptives (Catul. 26-28, etc. ; voir plus loin la typologie).

21 - Les autres modulations métriques portent, elles aussi, la marque d'un vigoureux talent qui retrouve - au niveau du contenu - les tonalités d'une sensibilité romaine, pour la strophe saphique (tetrastichon sapphicum), dans deux poèmes importants: Catul. 11 et surtout Catul. 51. Catulle - comparé à Horace - est plus proche de Sappho, notamment pour l'émulation mimétique de la phrase dans le carmen 51 . Il admet une base initiale trochaïque et il néglige parfois les coupes. Modèle :

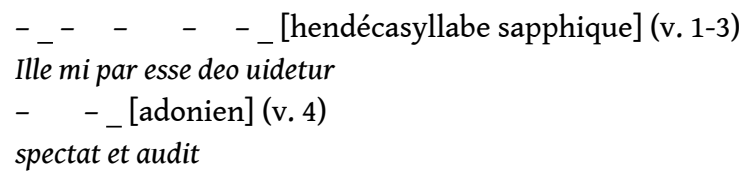

On remarquera ensuite, dans une classe distincte, les trois factures d'un couplage glyconéen + phérécratéen :

a. le vers priapéen de 15 syllabes, dans le pittoresque Catul. 17, à pointes ironiques :

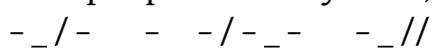

o colonia, quae cupis / ponte ludere longo

b. la strophe à 4 vers du carmen 34 :

$$
\begin{aligned}
& \text { Dianae sumus in fide } \\
& ---\quad-/ / \text { [pher] (v. 4) } \\
& \text { puellaeque canamus }
\end{aligned}
$$

c. la strophe à 5 vers du carmen 61 (Hyménée) :

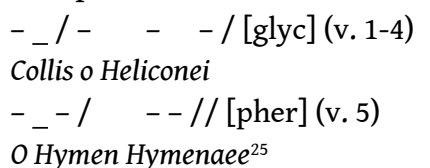

Un autre type de vers contient les volutes très larges (de 16 syllabes!) d'une 'rangée' périodique: l'asclépiade majeur (Asclepiadei maiores) du carmen 30. Rangée à double déclic :

$--/-\quad-/-\quad-/-\quad-U$

Alfene immemor at/que unanimis/false sodalibus

Pour les pièces versifiées kata stichon, signalons enfin quatre types de rangées iambiques :

a. le vers iambique pur (trimètre iambique de 12 syllabes), des carmina 4 et 29 :

Phasellus ille quem uidetis hospites [respecte strictement la loi de Porson]

b. le trimètre iambique, Catul. 52 :

Quid est, Catulle? quid moraris emori? 
Le vers initial devient dans le poème 52 un refrain, par son itération obsessive : clôture du discours, réalisant un effet d'enchâssement ${ }^{26}$. De surcroît, le contour terminal de chaque trimètre appuie l'intonation interrogative (ou 'indignée') par une coïncidence avec l'ictus du syntagme qui occupe ces dernières positions;

c. le trimètre iambique hipponactéen ou choliambe (scazon), dans lequel chaque iambe final s'alourdit et prend un contour 'boiteux', Catul. 8, 22, 31, 37, 39, 44, 59, 60 :

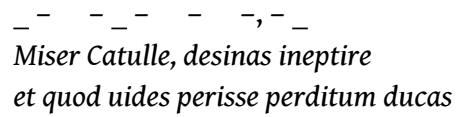

d. le tétramètre iambique catalectique (septénaire), Catul. 25 :

Cinaede Thalle, mollior cuniculi capillo

Le rythme imprime ici au débit une allure haletante, comme la parabase d'une comédie (avec une forte pause/diérèse, qui découpe le syntagme final de chaque vers, après le premier dimètre).

$\mathrm{Au}$ bilan de ces recherches dans le domaine des factures métriques, j'ajouterai trois séries de remarques concernant le profil discursif d'ensemble du corpus catullien et sa tripartition.

1. Si nous considérons les 61 pièces du libellus - premier volet d'un corpus ou 'recueil' telles que nous les lisons dans l'ordre des manuscrits, nulle part on ne trouve d'hexamètres dactyliques et, par ailleurs, trois pièces fragmentaires (18-20) ne figurent plus dans nos éditions, car des brindilles furent transcrites 'par intrusion', après avoir été disloquées d'un autre corpus (probablement celui de priapées). La physionomie polymétrique du libellus correspond au critère de mixité qui a déterminé l'assemblage des carmina dans les anthologies ou les « guirlandes » dont les factures présentaient les attraits d'une alternance de pièces versifiées, issues des collections alexandrines, regroupées auparavant selon l'appartenance des poèmes aux différents genres: hymnes, 'odes triomphales' (epinikia), thrènes, dithyrambes, péans, etc. Arrivée au terme de son déploiement, la 'guirlande' catullienne a pu circuler sous la forme d'un libellus indépendant, connu par la tradition littéraire dès l'Antiquité. Pourtant, dans la structure du volume d'origine, rien n'aurait justifié l'absence des textes brefs versifiés en distiques (comme les innombrables épigrammes érotiques chez les Alexandrins), dont le contenu s'accordait avec la tonalité des poèmes qui gravitent autour des erôtopaignia, parmi d'autres thèmes aux arguments nettement reconnaissables. En réalité, plusieurs pièces, versifiées en distiques élégiaques - insérées par la tradition manuscrite qui nous est parvenue dans la troisième section - s'adapteraient mieux au contexte du libellus primordial, agencé par Catulle. Ainsi, le déballage amer des infidélités qui n'arrivent pas à le séparer de Lesbie (Catul. 72), les remarques méprisantes dirigées contre un témoin du ménage à trois (Catul. 83), tout comme le célèbre Odi et amo du carmen 85 , seraient des jalons sur le chemin d'une progression douloureuse, suivie depuis les premiers symptômes jusqu'à l'apogée, qui dépeint l'arrêt sur image d'un paroxysme (Catul. 51). Mais 'l'ordonnateur' a pu déplacer quelques pièces pour donner un aspect homogène au dernier volet, réservé aux distiques du poète. Quoi qu'il en soit, le scintillement d'un équilibre instable persiste tout au long du (premier) libellus transmis par nos manuscrits, car on ne saurait ignorer la complétude provisoire de l'intrigue amoureuse: péripéties d'un «amour-passion» dont le déploiement s'annonce imprévisible (voire même capricieux, avec des hauts et des bas), 
comme cela ne tardera pas à se vérifier, à distance d'une génération, dans le monobiblos de Properce ${ }^{27}$.

2. Quant au second volet (Catul. 62-64), il se distingue formellement par l'emploi de rangées longues isométriques, versifiées kata stichon (62 et 64 en hexamètres dactyliques, 63 en galliambes). Par ailleurs, au niveau thématique, n'oublions pas la configuration des topoi analysés par P. Veyne : tout comme les intrigues (mythèmes) de la tragédie, certains arguments de la fable avaient déjà mis leur empreinte sur la disposition narrative des 'poésies' lyriques, dont la trame se tissait autour de l'éros hypostasié - péripéties vécues par un personnage mythique, de convention (héros ou héroïne) ${ }^{28}$. Or, cette constante va resurgir d'une manière subreptice dans le 'recueil' catullien, lors de l'epyllion qui raconte les noces de Thétis et Pélée (Catul. 64). Il faut aussi compter avec les habitudes littéraires des neoteroi, qui favorisaient un agencement inattendu ou insolite des thèmes abordés, selon quelque chassé-croisé de la poikilia.

Comme on l'a vu, 'le deuxième volet' - ou la section centrale du corpus - contient au début un Hyménée (Catul. 62), dont les groupes d'hexamètres sont délimités chaque par fois par l'itération du refrain (l'appel d'Hyménée, cf. infra). Le déroulement d'une pareille performance ne correspond pas aux critères d'une véritable composition strophique. Il s'agit plutôt d'harmoniser le scénario d'un faisceau à l'autre, car l'ensemble nous est présenté comme la mise en scène d'une mélopée chorale à progression ternaire :

- v. 1-19 : évocation introductive du dieu Hyménée, transfiguré lors du cérémonial mis en branle par Vesper/Hesperus, étoile du soir dont la montée à l'horizon illumine le concours des jeunes, résonateur des chœurs amébées (amoibaion = cantilène des voix en alternance, dans le cadre d'une responsio). Aux émois des jeunes filles non mariées (puellae innuptae) répondent à tour de rôle, par strophes, les élans des jeunes gens, lancés pour obtenir la victoire dans le combat du rapt nuptial. Catulle s'est montré plus abrupt dans son infléchissement du modèle grec des hymenaia. Il a même doublé sa mise, par rapport à l'épithalame joyeux du carmen précédent (Catul.61), poème occasionnel, destiné à l'exaltation paisible des rites performatifs (convoi et deductio à la maison de l'époux), lors du mariage de son ami Manlius, fiancé à la candide Iunia (ou Vibia). Ici (Catul. 62), les chœurs sont des personae génériques, leurs strophes des 'méditations' graves;

- v. 20-58: le faisceau suivant thématise les vérités du message (noyau du carmen amoebaeum), au moyen de phrases interrogatives ou d'assertions rassurantes, chaque fois énoncées sous la forme de métaphores tirées du monde naturel et renforcées par le refrain du cérémonial, pour bien indiquer les cadences rituelles et ramener nos pas vers le centre du monde, comblé au gré des appariements nocturnes ${ }^{29}$. Les cycles de l'enchâssement fonctionnent sans heurts, avec une relance de l'appel mystérique, huit fois repris, pour boucler des strophes aux dimensions qui s'amplifient :

Hymen / o Hymenaee, / Hymen ades / o Hymenaee. // ${ }^{30}$

- v. 59-66: une dernière semonce exhorte la vierge à ne plus combattre; à céder au mari, obéissant également en cela à ses géniteurs, puisque sa virginité lui échoit comme « un tiers de son être ; les deux autres appartiennent aux parents, qui l'ont vouée à leur gendre, avec la dot $»$.

Dans toute son extension, l'architecture des poèmes à vers longs isométriques (Catul. 62-64) a généralisé la disposition par enclaves des séquences phoniques, des vocables et des thèmes coarticulés. Le carmen 63 se singularise parmi les aitia réservés 
au destin d'une personnalité légendaire. Il ne relate sans doute pas l'histoire d'un parèdre du culte de Cybèle, ni celle du berger Attis, enlevé par la grande divinité chtonienne d'Asie Mineure. On devrait appréhender ce discours narratif par le biais d'une lecture insinuante, suivant la rythmique des péripéties, amplifiée par saccades, jusqu'à la prière du témoin lucide (v.91-93), qui demande à l'inquiétante déesse Magna Mater orientale - d'épargner sa maison, de pousser d'autres fervents aux excès de l'enthousiasmos orgiastique. Le poème d'Attis n'est pas non plus une réplique aux souffrances de 'l'oisive jeunesse', lorsque le Véronais subissait les affres de sa passion pour Lesbie. Les présupposés qui tendent à décrypter des motivations historiques n'arrivent pas à nous convaincre, car on devrait accepter sans réserve « l'idée que dans notre carmen Vénus et Cybèle soient en quelque sorte des 'hypostases' de Lesbie ${ }^{31}$. De tels recoupements, très utiles, risquent de fausser les données du sous-texte. Pour l'analyse des factures que nous privilégions, l'essentiel nous est livré par les grandes avancées du texte, perceptibles dans les temps de l'écriture narrative, qui alterne visions et monologues ou discours, répartis sur deux jours (couplage de mouvements suivis par une coda). Le mouvement initial (v.1-38) débute ex abrupto: porté sur un navire, Attis arrive au rivage asiatique, touche d'un pied impatient la forêt phrygienne, pénètre les repaires sombres de Cybèle, tressaille dans un accès de folie et tranche d'un silex ses testicules. À partir de cette castration, ayant changé de sexe, il (ou elle...) tiendra des propos exaltés, se qualifiant au féminin. Son discours proclame dès lors la suprématie d'un état-nature innocent (à peine sorti de son involucre... androgyne...), fraternel envers la sauvagerie; d'où son alliance avec les Galli, émasculés eux-mêmes. Leur bruyant cortège, allié aux Ménades, s'insurge contre Vénus (v.17), protectrice des mâles (tandis qu'eux représentent la sexualité indifférenciée). Pourtant la nuit apporte la torpeur accablante, puis un lourd sommeil et la quiétude où se dissout « la rage furieuse de leur âme» (v. 38). Après une courte évocation du réveil (v.39-49), les séquences du deuxième jour font résonner une longue complainte-palinodie d'Attis (v. 50-73), ce qui amènera la péripétie d'un cruel affrontement (v. 74-77). Le discours comminatoire de Cybèle, inséré dans le récit (v. 78-83), précède l'épilogue des lions, qui emportent leur victime (v. 84-89), avant l'énoncé final d'un alter ego. La voix du poète narrateur - qui a mis un sceau (sphragis) sur l'ensemble achevé - fait résonner dans une dernière phrase la double anaphore d'une percussion de clôture (Catul. 63, 93) :

Procul a mea tuus sit furor omnis, era, domo; / alios age incitatos, alios age rabidos

- La pulsation du rythme dans le très long galliambe (versus galliambicus) du poème d'Attis provenait semble-t-il à l'origine d'un tétramètre ionique a minore. C'est-à-dire, en structure profonde, quatre fois le module ascendant $\left\{{ }_{-}\right\}$ou $\left\{{ }_{-}-\right\}$, avec la catalexe et la résolution fréquente des longues des temps forts et faibles, surtout en fin de vers (rangées périodiques). Ceci favorise le renversement du profil iambique (par 'anaclase' du iambe, devenu trochée) et, par endroits, la substitution des longues. D'où l'émergence des pyrrichies (chaîne de pyrrhiques), du type :

$$
\begin{aligned}
& \{+, \quad \ldots\}: \\
& -,-,-/ \quad-, \\
& \text { Super alta uectus Attis celeri rate maria (v. 1) } \\
& \text { Phrygi(um) ut nemus citato cupide pede tetigit (v. 2) }
\end{aligned}
$$

31 Les séquences expressives de brèves (souvent issues des résolutions) et leur coïncidence avec les ictus (accents de mot) dans la seconde partie du vers impriment au discours lyrique (narratif) un frémissement perpétuel : sensation de fuite ou de vol, inimitables diagrammes de l'égarement et, par instants, réveil d'un alter ego découpant la durée. 

epyllion à programme Les Noces de Thétis et Pélée (Catul. 64), axé sur la thématisation d'un concept binaire : l'appariement (union fondatrice d'un héros éprouvé et d'une déesse souche d'une généalogie) et le rapt fabuleux (thématisation et hypostases du rite nuptial, intercalées chez Catulle sous la forme des péripéties d'Ariane, deux fois 'ravie', par Thésée, son infidèle prédateur, et par Bacchus, son libérateur céleste). Dans un travail dédié à l'exégèse interdisciplinaire des mythes, nous aborderons les différents aspects de cette conceptualité.

3. En rupture de ban après la variatio, une troisième section du recueil (Catul. 65-115) a privilégié l'homogénéité au niveau des structures métriques : toutes les pièces utilisent le distique élégiaque, comme si la physionomie des contenus avait tendance à s'harmoniser avec le profil isométrique des vers. Mais là encore, il ne faudrait pas trop préjuger de l'interface des genres. Il s'agit plutôt chez Catulle des modulations du vécu et de sautes d'humeur, qui se répercutent d'un registre à l'autre, à l'intérieur de l'imaginaire poétique, à travers plusieurs mondes. Pour autant, les factures instanciées se laissent aborder par notre lecture comme un work in progress. Vu qu'on doit accepter le coup d'envoi, qui annonce le parcours des nugae, lancé à l'eau sous les auspices d'une navigation poétique ${ }^{32}$, il serait normal de retracer les mouvements de chaque libellus comme ceux d'une partition musicale. Pourtant, même ce type de lecture ne saurait s'accorder d'un trait avec les contours de l'opus catullien. Car pour la mise en page de ses propres aveux, l'amant récusait la pédanterie d'un Antimaque (cf.Catul. 95, 10), auteur prolixe de la Lydè, amas de complaintes amoureuses (mega biblion honni). Les indications du "livre "-agrès de son enchaînement - relèvent derechef d'une structure indiquée saltim (d'une manière allusive), par le miroitement des touches. Il faudrait départager les enjeux d'une étude focalisée sur l'ensemble de l'œuvre poétique - comme certains ont essayé de le faire - pour tenter de préciser clairement les prémisses d'une méthodologie, avant de continuer l'analyse approfondie des factures spécifiques, caractérisées à partir des supports textuels de la tradition manuscrite. Du point de vue de la répartition par sous-classes thématiques, les pièces en distiques du troisième volet (Catul.65-116) appartiennent soit au genre des 'élégies nobles' complaintes ou variantes de la consolatio -, soit à celui des élégies 'amoureuses', soit au genre 'polyédrique' des épigrammes.

Finalement, n'oublions pas les matériaux et la configuration substantielle du textus receptus que les philologues récupèrent comme un produit fini de la textualité - ou interpretandum -, proposé au lecteur qui devient un destinataire virtuel. Tout spécialiste de l'ecdotique vient alors à la rencontre de l'interpres, pour affermir le message d'origine, livré par une lecture-décodage du texte transmis. Chaque interpretatio d'origine comporte également des apports corrélatifs de la divinatio (et parfois ceux de la correctio/ /emendatio), filtres superposés aux indices d'une coarticulation génétique, dont les séquences ont précédé la mise en place de l'ordre qu'on s'efforcera de retrouver, grâce à l'établissement du 'texte critique'.

\section{Pour une typologie des factures thématiques d'auteur}

Dans ces conditions, le repérage d'une typologie des textes cherchera en premier lieu à caractériser l'expressivité des factures catulliennes récurrentes et le substrat d'une thématique d'auteur. Les critères d'une sémiose plurielle nous invitent à (re)considérer 
patiemment les péripéties d'un substrat biographique disloqué par la 'fureur de vivre'. Je tenterai donc sommairement d'esquisser un classement typologique des pièces, regroupées selon la tradition manuscrite, dans l'ordre du textus receptus, sans négliger les aspects corrélatifs de la véritable genèse textuelle, raccordée aux contingences du vécu et en même temps dominée - à des degrés divers de conscience - par la maîtrise catullienne d'un art rigoureux ${ }^{33}$. Dans les paragraphes précédents, j'ai insisté sur la répartition des factures métriques. Désormais, l'analyse corrélative des procédés formels et des contenus délimités devrait permettre de reconstituer un classement provisoire des sujets et des arguments, configurés dans les différentes séries de poèmes, à l'intérieur des 'genres' du dictamen littéraire. Dans ce qui suit, je proposerai une catégorisation thématique des classes, en fonction de la hiérarchie signifiante qui prend forme à l'intérieur du recueil (implicitement: un réseau de modalités coextensives au déploiement des ressources créatrices).

A. Les poésies de la section qui s'étend de Catul. 2 à Catul. 11 (et leur continuation jusqu'à l'épithalame Catul. 61) attestent dès les premiers de la présence du sous-texte des amours, dont le noyau central serait une love affair avec Lesbie. Une réverbération de ce leitmotiv obsessionnel se prolongera bien au-delà du libellus ${ }^{34}$. L'expression des appels amoureux et la tonalité des louanges contrastent avec les apostrophes, les invectives, les aveux de désarroi ou les escarmouches aux cibles diverses, qui alternent, comme les tournants de la concatenatio: inexorables cadences de l'humeur et de la passion. La projection du passer (Catul. 2-3), avec des connotations érotiques troublantes (dont Martial se souviendra dans une imitation plaisante), fait place au motif thématisé du baiser (Catul. 5 et 7 ; cf. supra), suivis par le monologue de l'ego scindé (Catul. 8), qui précède l'apogée de Catul. 51 (arrêt sur image ?) et les accents de la crise sans issue (Catul. 58). Des études - par centaines... - en ont fait leur banc d'essai. Quoi qu'il en soit, le simple constat des alternances du cœur ne saurait nous renseigner d'une manière satisfaisante sur le tissage intertextuel des poèmes.

Une particularité des plus intéressantes concerne le foyer d'intensité qui se disloquait déjà dans Catul. 8 (Miser Catulle, desinas ineptire!). Dès cette époque, la jalousie - relayée par le souvenir des incidents pénibles - déclenchait une objectivation de la servitude amoureuse ${ }^{35}$. Sur ces entrefaites, beaucoup plus tard (sans doute après 55 av. J.-C.)*, Catulle compose le carmen 11 (versifié comme Catul. 51 en strophes saphiques), où résonne, cinglant, le 'mot de la fin'. Un adieu - par voie de métaphores - doit clore son aventure amoureuse avec Lesbie :

Furi et Aureli, comites Catulli,

siue in extremos penetrabit Indos,

litus ut longe resonante Eoa

tunditur unda,

siue in Hyrcanos Arabasue molles

seu Sagas, sagittiferosue Parthos,

siue quae septemgeminus colorat

aequora Nilus

siue trans altas gradietur Alpes

Caesaris uisens monimenta magni,

Gallicum Rhenum, horribilesque ulti-

mosque Britannos,

omnia haec, quaecumque feret uoluntas

caelitum, temptare simul parati,

pauca nuntiate meae puellae

non bona dicta : 
Cum suis uiuat ualeatque moechis, quos simul complexa tenet trecentos, nullum amans uere, sed identidem omnium

ilia rumpens ;

nec meum respectet, ut ante, amorem,

qui illius culpa cecidit uelut prati

ultimi flos praetereunte postquam

tactus aratro est.

Ce poème d'une importance capitale a provoqué de nombreuses controverses, dues premièrement à la disproportion qui affecte l'énonciation du message transmis, après la très longue phraséologie hyperbolique des strophes introductives. Une mission est confiée à deux amis de Catulle (qui se nomme lui-même, comme si l'énoncé focalisait sa présence de l'extérieur). Il enjoint aux camarades interpelés (ses comites) de l'accompagner dans une aventure lointaine, jusqu'aux frontières du monde où arriveraient les armées césariennes... (v. 1-12). Mais qu'ils se chargent également de cette requête: "Ô vous tous qui dans ces contrées êtes prêts à affronter les périls auxquels m'exposera la volonté céleste, portez à ma maîtresse [mea puella...] ces quelques paroles sans douceur... » (v. 15-16). Le mandat qui suit n'est qu'une dernière insulte adressée à la bien-aimée d'antan. Invective acerbe, à laquelle s'ajoute néanmoins - en ultime écho d'une grande amertume - la phrase poignante, porteuse d'une image délicate, très évocatrice pour tout connaisseur de la diction homérique : "Qu'elle vive heureuse avec ses trois cents amants, / qu'elle serre en même temps dans ses bras, / sans en aimer vraiment un seul, mais en cassant / leurs flancs à tous ! / Et qu'elle ne tourne plus ses regards comme jadis vers mon amour; / par sa faute il a flanché, comme, tout en marge du pré, / la fleur que vient de toucher / la charrue au passage » (v. 17-24). Un des modèles pour ce topos remarquable se lit chez Homère, où la tête d'un héros, blessé à mort, « penche de côté, tel, dans un pré, le pavot qui penche sa tête, sous le poids de son fruit et des pluies printanières » (Il. 8, 306-308). Plus près de ses auteurs d'élection, le poète retrouvait l'image symbolisante dans une épigramme de Méléagre, qui dépose sur la tombe d'Héliodora l'offrande de ses larmes : «Hélas! où est la fleur que j'ai tant désirée, Hadès me l'a ravie... / Sa beauté printanière dans la poussière gît souillée ${ }^{36}$.

39 Comme la genèse du carmen 11 (Furi et Aureli comites...) date d'une époque tardive vers 53-52 av. J.-C., aux alentours des campagnes de Jules César en Grande-Bretagne -, il est évident que son insertion dans le voisinage des poèmes plus joyeux ou plus bariolés produit l'effet d'un terrible 'désaveu', qui s'annonçait déjà dans les termes du monologue de l'être scindé, dans Catul. 8 (Miser Catulle...; cf. supra). Ici, toutefois, la rupture est consommée. Ou plutôt, on aperçoit les rebords de cette déchéance avant les autres visions de l'unique /vrai/ amour qui se profilait en contre-jour ${ }^{37}$. Le renversement des séquences n'est pas un simple accroc. Il est voulu par l'auteur, qui a choisi un emplacement parmi les quinze premières pièces du libellus, lorsque la plus grande partie des polymetra prenait déjà la physionomie d'un ensemble achevé. Le choix du mètre va dans le même sens: le désaveu de Catul.11 et le poème de l'extase (Catul. 51 : Ille mi par esse deo uidetur) sont les seules pièces à versification saphique; les thèmes contrastent, alors que le crescendo devient chaque fois insoutenable.

Globalement, la manière spécifique de métaphoriser les factures et la portée signifiante des poèmes relèvent chez Catulle d'une architecture concentrique. Celle-ci prédomine parmi les critères d'agencement, car les motifs obsédants animent un espace clos de 
l'imaginaire hanté par le désir (cupido). Ainsi, l'amour fou des jeunes gens qui s'éprennent ne connaît pas les demi-teintes ou la trêve. Car la promiscuité risque d'animer le scénario. Juventius, quelque tendron ou un 'éromène' qu'on recherche à travers les portiques virevoltent autour d'un erastès, comme Lesbie qui se donne à plusieurs amants, et la jalousie attise des ressentiments épisodiques: les images obscènes, la véhémence des injures accablent celle qu'on a exaltée auparavant. Chez Catulle, un retour de flamme brille soudainement; il sauvegarde le souvenir de l'unique, de celle qu'on a aimée par dessus toute chose - et «la joie venait toujours après la peine... » Bientôt, le regret lancinant s'élance vers d'autres fantasmes et cette fois il rencontre une histoire inscrite dans la région du mythe, dotée d'un merveilleux ascendant : celui d'hypostasier des vérités et de les accorder avec le subconscient. La dernière séquence des polymetra (Catul. 55-61) culmine avec un premier épithalame (Catul. 61 = pièce commandée ?) en mètres lyriques stylisés, alors que l'Hyménée Catul. 62 fait partie de la section centrale (Catul. 62-64), réservée d'un bout à l'autre à la versification kata stichon des poésies en vers longs. Du côté des contrastes, nous pourrions dire que plusieurs fascicules restreints de poèmes érotiques (issus peut-être des erôtopaignia) sont des textes dictés par l'horreur ou la satiété, qui se révoltent ou réagissent contre 'l'empire' de Vénus et les abus de sa toute-puissance. Or le principe des structures interférentes commande ici des relances thématiques, d'une section à l'autre, comme nous le montre le psychodrame d'Attis (Catul. 63), analysé ci-dessus. Néanmoins, sur un plan parallèle des interférences, une exploration à travers les polymetra du libellus (Catul. 1-61) nous révèle aussi dans certains poèmes la transposition sui generis des images nostalgiques d'un état faste d'innocence juvénile, miroitement réfléchi par les expériences (manquées...) du bonheur fugace ou des promesses nuptiales (Catul. 34 et 50). La succession imprévue des rencontres et des querelles amoureuses amènera dans le carmen $68 \mathrm{~b}$, au milieu de notre troisième section (Catul. 68b), l'évocation de l'unique jouissance 'quasi maritale' avec Lesbie, lors d'une escapade furtive dans la maison d'Allius (Catul. 68b, 68-69):

Isque domum nobis isque dedit dominae

Ad quam communes exerceremus amores.

Ce fut lui qui nous fit don d'une maison, lui qui la donna à ma maitresse / pour accomplir nos amours mutuels.

41 Parfois on pourrait se demander : la pénombre des contrastes ou la simple diffraction d'une flétrissure qui avait marqué d'une manière inoubliable chaque nouvelle phase dans la biographie de Catulle sont-elles encore perceptibles lorsque nous analysons la mise en abîme des 'pré-textes' littéraires? Il est indispensable de sonder l'arrière-plan de la poikilia (alternance des motifs 'variés').

B. Formant une classe thématique à part, un bon nombre de pièces retracent dans le recueil les péripéties d'une sexualité aux multiples facettes, parmi lesquelles font saillie les aventures homosexuelles, en alternance avec des interludes pittoresques, 'rabelaisiens' (avant la lettre) ou acerbes, qui thématisent l'envie, le désir (cupido) presque insatiable...-, mais aussi l'attachement délicat, la dérision (hénaurme...), les tiraillements de la fidélité, la gestualité 'païenne' des actes charnels. Ainsi, l'évocation du mignon Juventius (qui se pointe dans plusieurs sections : Catul. 24, 48, 81, 99) comme celle d'une tendre Ipsithilla (Catul.32) contrastent avec les caricatures acerbes, dépourvues d'aménité, plaisanteries 'fielleuses'. Les expressions du malaise social et politique reviennent comme autant de constantes, dans les polymetra et dans les épigrammes de la troisième section: cycle à connotation anti-césarienne des abus de 
Mamurra « Laverge » (Catul. 29, 94, 105, 114-115), turpitudes et manœuvres sournoises d'un Gellius (Catul. 74, 80, 88-89, 91, etc.). Du côté des amitiés homosexuelles et des coteries littéraires, les visites sont souvent un prétexte soit pour en découdre avec les poètes délétères (dont Suffenus, Catul. 14, 19, 22), soit pour deviser avec des congénères sympathiques (Licinius Calvus, Cinna, Cornificius). Sans rapport direct avec les symptômes du vrai pathos (subjectif), signalons au gré des 'occasions', parmi les séquences polymétriques, le 'déportement' des invectives et des poèmes figuratifs : hendecasyllabi équivalents des iambi, qui "parlent» par métonymie (à l'instar des quolibets d'Archiloque ou d'Hipponax), comme cette réprimande qui menace un voleur dans Catul. 12 :

Quare aut hendecasyllabos trecentos

exspecta aut mihi linteum remitte!

D’où l'importance des réalisations expressives, dont nous avons examiné séparément les contours métrico-syntaxiques. L'auteur des carmina pouvait manier ces agrès comme des flèches ou un boomerang, dans son élan d'affronter la vie, de se libérer des contraintes, de 'vider des querelles' - avec la société, avec le 'sexe' ou avec des rivaux -, de même qu'il peut utiliser des contours métriques similaires pour s'épancher parmi ses amis.

Au centre du recueil, la discursivité narrative aux allures nobles utilise un dosage particulier d'éléments repris aux Aitia et à l'epyllion. L'entablement des carmina maiora 62 à 64 (pour certains, y compris Catul.61) faisait pendant aux polymetra, dans une section distincte des poésies à vers longs (poḯseis dont l'envergure plus imposante surclassait les dimensions modestes des poemata) ${ }^{38}$.

45 C. L'emploi des thèmes et des figures stylisées de la mythologie proposait le surfilage 'exotélique' d'un parcours sui generis des néotériques, continuateurs de l'epyllion alexandrin, dont Callimaque se posait en chef de file (à côté peut-être de Théocrite et de cet Euphorion que nous connaissons très peu), instigateur d'une rivalité avec Apollonius de Rhodes, injustement 'snobé' par les poetae noui. Chez Catulle, un faisceau de thèmes contrastés se déploie dans la série des mythopoèmes : (Catul. 63 - Attis), suivi par (Catul. 64 - Les Noces de Thétis et Pélée), diptyque encadré par la transposition stylisée d'un Hyménée - Catul. 62, poésie d'ouverture ${ }^{39}$ - et par la réverbération à distance d'une imagerie célébrative : Catul. 66 - La Boucle de Bérénice.

Il nous incombe ici de souligner qu'il est inutile de postuler l'existence de coupures violentes après les carmina docta de la troisième section. Il s'agirait plutôt d'un sousensemble.

D. Selon des aperçus qui pourraient fournir l'interface de plusieurs théories, les remous de la passion pour Clodia/Lesbie avaient leurs points de chute dans une ode célèbre (Catul. 51) "imitée » de Sappho et dans l'enclave 'élégiaque' du carmen 68b, moments d'extase contrebalancés dans le libellum par une séquence de poèmes acerbes ou mordants (Catul.52-60). Survenait ensuite la section des poèmes à programme (C). Ceux-ci trouvèrent leur contrepartie dans les aveux qui nous communiquent les tonalités d'une désolation sincère, modulée 'à sa façon', dans quelques poèmes très particuliers, versifiés en distiques élégiaques. Cette mouvance du groupe $\mathrm{D}$ rejoint le déploiement des thèmes graves ou lancinants qui évoquent le traumatisme subi à la mort du frère (surtout après la visite au monument qui abritait ses reliques, en Asie Mineure). Le premier témoignage se distingue tout au début de la section élégiaque (Catul. 65, dédié à <Quintus Hortensius> Ortalus), acheminé par un message oratoire 
introductif du type recusatio. En fait, dès le carmen 67 (topos 'décalé' ou agrès thématique de la " porte ») et jusqu'à la fin du recueil (Catul. 116), l'ensemble des pièces versifiées fait partie d'un lot compact d'épigrammes ${ }^{40}$, mais toutes les enclaves qui ramènent au premier plan le sentiment d'un vide irrémédiable après le décès du frère sont les foyers d'une diffraction qui a modifié les visées de l'auteur. À l'exception de l'excursus occupé par l'histoire de Laodamie (Catul. 68b, 73-105), la mythologie n'a plus de résonance dans le dernier sous-ensemble (D) du recueil, et les tonalités mélancoliques interrompent quelques brèves éclaircies, tandis que les attaques vindicatives marqueront leur prédominance. Pour donner le ton, treize pièces évoqueront encore Lesbie (Clodia) et par deux fois un thème funéraire nous transmet le témoignage d'une station à proximité du tombeau de l'être cher. L'épigramme 101 modifie la portée d'un épikédion et survole posément le rituel de l'offrande apportée "à la cendre muette du frère ». L'autre pièce (Catul. 96) tient lieu d'une consolatio pour Calvus, tourmenté par le souvenir de Quintilia, décédée toute jeune. Là aussi une présence du regret et de l'audelà plane autour de la souvenance, car la gentille Quintilia « est moins affligée de sa mort prématurée qu'heureuse de ton amour " !

Celui qui systématise maintenant l'ensemble des opinions critiques et des redites se rend compte que les débats des spécialistes de Catulle tournent autour de ces quelques apories majeures:

- Les poèmes à vers longs (Catul. 62-64, y compris l'épithalame Catul. 61) forment-ils effectivement un deuxième livre du 'recueil' des poèmes catulliens qui précéderait directement le troisième livre, dernier ensemble réservé aux pièces versifiées en distiques élégiaques?

- Ou bien doit-on nuancer d'une manière plus exacte la typologie des genres et repérer une division à quatre sections? On aurait alors une partition 'à tiroirs' qui voudrait installer un ordre attesté par la configuration ultérieure d'autres volumina (par exemple, ceux des Élégies de Properce et des Odes horatiennes). Pour Catulle le rangement serait virtuel...

- Livre I: il regrouperait les polymetra (Catul. 1-60) dans un volume restreint, mis en circulation et connu per excellentiam sous le titre générique de libellus (terme utilisé d'une manière moins stricte par le poète lui-même).

- Livre II : la section des poèmes « doctes » à vers longs (carmina maiora), qui forment la partie centrale (Catul. 61-64) du corpus (ou 'recueil'), regroupe des pièces programmatiques, dont certaines pouvaient circuler séparément, dès l'Antiquité tardive, comme cela ressort de la tradition manuscrite de $\mathrm{T}$, reproduite par le copiste du Codex Thuaneus au IX $\mathrm{x}^{\mathrm{e}}$ siècle - une anthologie qui retient uniquement l'Hyménée (Catul. 62).

- Livre III: nouvelle série des pièces 'doctes' (Catul.65-68b), de longueur variable, interconnectées. À commencer par le poème-dédicace à 'Ortalus' (Catul. 65), qui s'apparente à l'épître de remerciement (selon Catulle, un epistolium), pour faire la transition vers le carmen 66: la célèbre Boucle de Bérénice, pièce d'apparat, imitée de Callimaque. À cette 'guirlande' tressée librement - comme chez Méléagre - s'est ajouté le carmen 67 : variations inattendues (aprosdoketon) sur le thème d'un Dialogue avec la porte. La personnification de la porte semble donner une autre vie aux objets qui parlent par delà les conventions maniéristes des ténors alexandrins de l'épigramme amoureuse : Saepe illam audiui furtiua uoce loquentem / solam cum ancillis haec sua flagitia... (Catul. 67, 41-42)

Les pièces élégiaques (proprement dites) qui ferment la spirale (Catul. 68 et $68 \mathrm{~b}$ ) sont des poésies appartenant au genre de la consolatio, dédiées à des amis (Manlius et Allius?). Accolée dans les manuscrits au poème 68 , la pièce 'docte' corrélative Catul. $68 \mathrm{~b}$ combine les 
récits enclavés (tressés ad incastro!) de plusieurs expériences, dont celles qui suivirent le décès de son frère, après la réconciliation temporaire avec Lesbie-Clodia.

- Livre IV: dans ce compartiment on regrouperait un lot considérable d'épigrammes (Catul. 69-116) qui avaient fini par se constituer en 'sous-section' autonome, dans la partie finale du volumen.

Il est inutile toutefois de séparer un quatrième livre du tronc des autres pièces qui sont regroupées après les poèmes longs (Catul. 62-64). Non seulement depuis le carmen 65 jusqu'à la fin du recueil (Catul.116) le distique élégiaque s'est imposé dans la poésie (comme il adviendra chez la plupart des lyriques romains qui ont cultivé ce genre du temps des empereurs), mais les arguments eux-mêmes et leur tonalité poursuivent le filon des souvenirs douloureux, des querelles amoureuses, des prises à partie dans la foire des vanités.

\section{Derniers regards}

49 À la suite de ces controverses sur les 'partitions du livre', j'oserais toutefois 'récupérer' le profil d'un Catulle poeta doctus, personnage d'autant plus attachant que son œuvre telle que nous l'ont transmise les rares manuscrits anciens - contient des tableaux de mœurs crayonnés sur le vif, qui ont permis de reconstituer les ambitions littéraires des 'néotériques' romains. Même si les outrances 'catulliennes' se colorent parfois d'une animosité à peine supportable, son ego défie - ou transcende - les frontières d'une poétique des sujets convenus. Il a franchi implicitement les barrières de l'artifice, ayant accédé aux sortilèges d'une expression vraie des souffrances et des joies, dans un langage qui n'a pas son pareil. Un exemple d'imprévu - aprosdoketon reproduit cidessus - nous confronte avec le symbolisme de la fleur (d'habitude celle du pavot) brutalement arrachée. C'est un des plus anciens topoi du langage figuré des lyriques, que l'on retrouve d'un millénaire à l'autre - notamment chez Rilke (Sonnets à Orphée) et dans le premier recueil qui a lancé Celan: Mohn und Gedächtnis (persistance d'un symbolisme d'empreinte monadique) ${ }^{41}$. Quant au succès remporté par le "perfectionniste du lepos » (selon la formule de Franco Bellandi) ${ }^{42}$, la postérité s'est chargée de faire le tri. Et même si des copistes grammairiens - grammatici = spécialistes du beau langage - nous ont légué des recueils charmants du genre Catalepton et un epyllion comme l'Aetna, ce sont là des œuvres mineures qui n'arrivent pas à livrer le message d'une véritable personnalité poétique. À l'opposé de ces anonymes, l'auteur du libellus dédié à Nepos aura toujours la cote d'un novateur fascinant ou, du moins, il restera, contre vents et marées, ce prototype d'amant éperdu, inconditionnel, destinatus ( ( ferme assujetti à son destin »), celui qui s'est aventuré lui-même dans la tourmente, de Vérone à Rome, parmi les gens apostrophés dans les carmina, femmes convoitées ou ingénues, hommes adonnés au sexe, 'dévoreurs de patrimoines' ou parasites, concitoyens de tout poil (la plupart grotesques). Il est vrai, dans ce monde où il s'ébat, le voici côtoyant des intellectuels de talent, ses compagnons poètes (comites, la plupart désargentés), certains noceurs espiègles, érudits méritants (qui s'adonnent au ludus et aux facetiae), et d'autres encore, des prétentieux adeptes des Muses (pessimi poetae, Catul. 14). Or il est pris dans la ronda dei piaceri avec ses amis de tout bord, louvoyant, comme eux, à l'affût des tendrons (puellae ou délicats mignons), mais il guette aussi la jeune beauté sans pareille, parmi les ingénues et les prostituées, et le voici alors, malgré la solitude, malgré ses déconvenues douloureuses (fortuna casuque oppressus acerbo), toujours hanté par les simulacres d'une mythologie archétypale. 
Depuis des lustres, les tâcherons des concours universitaires ont affadi et dénaturé le tableau des circonstances immanentes à la singularité de cette poétique implicite d'auteur. En réalité, parmi d'autres destinées littéraires, l'œuvre de Catulle témoigne d'une révolte lucide qui a opéré la transmutation libre, déroutante, des épreuves subies : il exprime à sa manière la réverbération du grand amour déçu et le désarroi après la mort du frère bien-aimé. Nous avons analysé sommairement quelques échantillons de ses emportements lyriques aux abords de l'extrême. Il resterait encore à sonder la filiation de cette écriture avec les épodes véhémentes d'Archiloque, car Catulle remonte ici aux sources et devance Horace sur le terrain des synergies du mètre avec les factures grammaticales et prosodiques des poèmes, alors que l'intertextualité avec les épigrammes des Alexandrins fonctionnait déjà depuis quelques décennies, offrant un vaste arsenal de sujets et de tournures. Cependant, Catulle a filtré tous les apports du 'néotérisme' : la plupart des modules métriques dont nous avons examiné le schéma surgissent dans le réseau du libellus à point nommé, car les modulations s'accordent avec son tempérament fougueux (comme pour le galliambe, qu'il a réinventé). Pulsation du rythme de combat, invectives, prières d'un amoureux qui s'éprend avec tout son être de l'impudente Clodia, puissantes vibrations des mètres éoliens et des hipponactei, tous ces remous infléchissent les volutes d'un bonheur éphémère, le miroitement des faveurs révolues, la hargne contre les fantoches vicieux et les abus de Mamurra. En clef de voûte, on perçoit l'alternance des trois instances, jamais... circonvenues : à Lesbie, « qu'il a aimée seule, plus que lui-même et que tous les siens ", s'oppose le cinglant alter ego, capable de lui tenir tête, mais qui guette dans un adyton la prémonition diffuse des malheurs ou des péripéties à venir (instance du fatum). Le poète donne voix à cette inquiétude, après la mort de son frère, lorsqu'il s'excuse auprès d'Ortalus (Catul. 65, 3-4) :

Nec potis est dulcis Musarum expromere fetus

Mens animi tantis fluctuat ipsa malis

Les doux enfantements des Muses ne peuvent guère germer dans mon âme agitée par autant de maux...

51 Dans cette phrase aux allures métaphoriques, mens animi paraît un pléonasme intraduisible. Il transpose un dualisme foncier, tout à fait remarquable, des 'factures catulliennes' : animus, « la volonté »<sensible>, et mens, « la raison », s'interrogent ou se provoquent sans répit, et la configuration discursive du langage correspond parfaitement au même tour d'esprit (répercuté par les poèmes). Les travaux récents que nous venons de citer commencent à peine à valoriser l'importance que revêtent les figures d'encadrement et la concatenatio. Il me semble que des tournures obsédantes aux accords très divers - scrittura fugata et ritournelles, sommations ou échos, refrains, dénégations - trouvaient leur contrepartie non seulement dans le parcours existentiel de Catulle, mais aussi dans sa prédilection certaine pour une écriture qui enclave le récit et la plupart des énoncés dans un réseau parallèle qui nous transporte soit à l'orée des époques imparties à la vie des générations, comme aux jours des Argonautes et des noces de Thétis, soit au seuil des grands émois qui scelleront l'union amoureuse l'exigeant foedus - où s'épanouit la fides païenne des âmes et des corps qui s'éprennent :

Nulla fides ullo fuit umquam <in> foedere tanta

quanta in amore tuo ex parte reperta mea est.

Jamais quelqu'un n'a mis tant de fidélité dans un pacte / comme celle qui se trouve

dans mon amour ${ }^{43}$... 
52 'envoi', les relais de l'écriture, dédiant son lepidus libellus à Nepos (Catul. 1), qualifié lui aussi par ses doctae et... Iuppiter! laboriosae cartae ${ }^{44}$. Mais que représente finalement le voyage de son livre si on le compare à la fortune du «Monobiblos » de Properce, à partir d'un discours auto-référentiel qui ne cesse jamais de s'amuser avec la performance <multiple> des 'objets littéraires'? Dans une approche qui me semble tout à fait légitime, les jugements de valeur ont surtout insisté sur la violence et les emportements lyriques d'un poète sincère. Il me paraît toutefois qu'il faut aussi considérer, au même titre que les poussées foncières d'un instable tempéramental, les motivations anthropologiques ('païennes') de son comportement, soumis aux instances supra-individuelles (souvent personnifiées), qui avaient leur emprise sur la sensibilité des Anciens (à Rome, comme en Hellade). Ainsi, 'l'envie' (invidia, gr. phthonos) et le 'mauvais œil' (fascinum, gr. baskanion) connotaient fortement les ingrédients de la passion et la manifestation des instincts, l'effroi des rapports sexuels (lato sensu), les désirs et la violence dans la nature sauvage (un des patrimoines de Cybèle). D'où aussi l'ambivalence et les travers de la jalousie $\approx$ envie, celle qui tourmente les amants (sur le plan interpersonnel) et celle qui focalise le rite des sarcasmes priapiques ${ }^{45}$ ou le ressentiment inassouvi de quelques semblables 'envieux' et vindicatifs, 'mauvais' ou inhumains, desséchés... intolérants ${ }^{46}$.

Aux antipodes, dans un monde civilisé, la thématique du jeu littéraire se dessine avec ses pièges $-\mathrm{y}$ compris toute une gamme d'appellatifs, déployés pour désigner chez Catulle les supports ou les métonymies de l'écriture, connotée par la spécificité de certains genres, qui se raccordent d'emblée aux comportements des lettrés et de leur public : liber, libellus, carta, codicilli, palimpsestus, iambi, papyrus, hendecasyllabi, uersiculi et j'en passe... Par endroits, ces 'paragrammes' sont utilisés dans une charge/invective. Ils arrivent parfois 'sous la main' du scriptor/ /auteur, qui veut manifester son altérité, n'hésitant pas à dénigrer avec mépris l'écriture-objet (cacata carta) d'un rival, poète balourd 'Volusius' (alias Tanusius) ${ }^{47}$. Au bout du compte, dans ce contexte, on peut s'interroger sur le dessein de 'notre' auteur, qui s'était résolu un beau jour à rassembler dans un liber ses écrits en vers, distribués aux amis (accompagnés de quelques nouveaux poèmes). Les controverses et les savantes disputes iront toujours bon train : jusqu'où doit-on pousser les hypothèses, par delà ces mots qu'il a dictés dans le plaisant envoi du libellus à Nepos? D'autres encore n'auront de cesse de rechercher des indices, pour diviser la matière de ses 'livres' et régenter enfin ce beau désordre. Il se peut que le poète n'ait même pas songé à terminer son labeur, surpris à moins de quarante ans par la mort et le désarroi. Pourtant, le projet du livre - ce livre qu'on s'apprête à lester, orné d'une belle dédicace, pourvu en même temps du «sceau » (sphragis) qui lui donne libre passage, avant même qu'il soit achevé - persiste par la fiction des pièces d'encadrement ${ }^{48}$ et le topos revenait constamment chez les auteurs d'épigrammes, du moins depuis Théognis. On a bien compris la portée des vœux formulés dans le poème d'incipit (Catul. 1, v. 8-10) :

Quare habe tibi quicquid hoc libelli,

qualecumque; quod o patrona virgo

plus uno maneat perenne saeclo

Dans le dernier poème du recueil (Catul. 116), tel que nous l'ont transmis les manuscrits, le message de la sphragis n'est plus désinvolte. C'est en émule de Callimaque 
que le poète fait semblant d'adresser - en imitateur des Aitia et des épigrammes gracieux - une dernière déprécation à Gellius, son rival vindicatif :

Souvent, à ton intention, j'ai cherché avec la passion d'un chasseur la forme sous laquelle je pourrais t'adresser des vers du descendant de Battos, pour te fléchir et t'empêcher de lancer sans arrêt tant de flèches hostiles sur ma tête; je vois

aujourd'hui que j'ai perdu ma peine, Gellius, et que mes prières n'ont servi à rien.

Finalement, Catulle réalise que son échange de 'traits' spirituels n'a pas eu l'aboutissement escompté. L'autre ne l'entend pas de la même oreille, ne se laisse pas 'radoucir' (carmina uti possem mittere / qui te lenirem). Donc, tout ce labeur fut inutile... Mais qu'à cela ne tienne! Dorénavant lui (poète antagoniste) saura contrer Gellius, et celui-ci paiera sa méchanceté un beau jour, rivé au supplice :

at fixus nostris [telis] tu dabi' supplicium. \#

Comme l'a finement remarqué Timpanaro, on a ici une allusion au supplice fatal de Remus (Enn., An. 95) :

nam $m i<t u>$ calido dabi' sanguine poenas ${ }^{49}$

Vindicative prédiction de la sphragis concernant la destinée du livre à peine achevé, qui devra suivre son chemin jusqu'au jour où Gellius sera châtié ! Et malgré les manœuvres de certains philologues qui voudraient désamorcer l'épigramme, la reléguant au début d'une série de pièces qui concernent 'l'affaire Gellius', il vaut mieux lui garder son aspect étrange et obscur, car elle annonce peut-être une fin de partie ${ }^{50}$. The rest is silence...

\section{BIBLIOGRAPHIE}

\section{Éditions et instruments de travail}

\section{Catulle}

AGNESINI A. (éd.) 2007, Il Carme 62 di Catullo, Quaderni di Paideia 5, Cesena.

BARDON H. (éd.) 1973, Catulli Veronensis carmina, Bibliotheca scriptorum Graecorum et Romanorum Teubneriana. Auctores romani, Stuttgart.

KROLL W. (éd.) 1980, C. Valerius Catullus, 6e éd., Griechische und Lateinische Schriftsteller Ausgaben, Stuttgart.

LAFAYE G. (éd.) 2002, Catulle. Poésies, $13^{\mathrm{e}}$ tirage revu et corrigé, CUF, Paris.

MCCARREN V.P. (éd.) 1977, A Critical Concordance to Catullus, Leyde.

MYNORS R.A.B. (éd.) 1958, C. Valerii Catulli Carmina, Scriptorum classicorum bibliotheca Oxoniensis, Oxford.

THOMSON D.F.S. (éd.) 1998, Catullus, repr. with corr., Phoenix. Suppl. 34, Toronto - Buffalo. 
WARRE CORNISH F. (éd.) 1995, Catullus; suivi de POSTGATE J.P. (éd.), Tibullus, $2^{\mathrm{e}}$ éd., revue par G.P. Goold, Loeb Classical Library 6, Cambridge (Mass.).

\section{Philodème}

GIGANTE M. (éd.) 2002, Il libro degli Epigrammi di Filodemo, Naples.

MANGONI C. (éd.) 1993, Filodemo. Il quinto libro della poetica: PHerc. 1425 e 1538, La scuola di Epicuro 14, Naples.

NEUBECKER A.J. (éd.) 1986, Philodemus. Über die Musik IV. Buch, La scuola di Epicuro 4, Naples.

\section{Les néotériques et leurs modèles}

CAHEN É. (éd.) 1922, Callimaque. Hymnes ; Épigrammes ; Les Origines ; Hécalé ; Iambes ; Poèmes lyriques, CUF, Paris [ $7^{\mathrm{e}}$ tirage : 2002].

DEGANI E., BURZACCHINI G. (éds) 1978, Lirici Greci: antologia, Florence.

TRAGLIA A. (éd.) 1974, Poetae noui: iteratis curis, $2^{\mathrm{e}}$ éd. revue, Poetarum Latinorum Reliquiae 8, Rome.

WALTZ P. et al. (éds) 1929-2002, Anthologie grecque. Première partie. Anthologie palatine, CUF, Paris, 7 vol.

\section{Sources secondes}

ADAMS J.N. 1982, The Latin Sexual Vocabulary, Duckworth Classical Essays, Londres.

BARBAUD T. 2006, Catulle: une poétique de l'indicible, Bibliothèque d'études classiques 47, Louvain Paris.

BARDON H. 1970, Propositions sur Catulle, Coll. Latomus 118, Bruxelles.

BELLANDI F. 2007, «Lepos» $e$ «Pathos»: Studi su Catullo, Testi e manuali per l'insegnamento universitario del latino N.S. 101, Bologne.

BIRT T. 1904, « Zu Catull's Carmina minora », Philologus 63, p. 425-471.

BUCHHEIT V. 1975, «Catulls Literaturkritik und Kallimachos », GB 4, p. 21-50.

CLAES P. 2002, Concatenatio Catulliana: A New Reading of the Carmina, Amsterdam Studies in Classical Philology 9, Amsterdam.

CRUSIUS F. 1958, Römische Metrik: eine Einführung, neu bearb. von H. Rubenbauer, Munich.

CUPAIUOLO F. 1965, Studi sull'esametro di Catullo, Collana di studi latini 10, Naples.

DANGEL J. 2002, « Catulle, carmen LXIV : mythe, amour et poétique », in P. Defosse (éd.), Hommages à Carl Deroux. I, Poésie, Coll. Latomus 266, Bruxelles, p. 127-141.

DEROUX C. 1989, « Catulle, poète de la justification et de l'argumentation », Ktema 14, p. 205-216. DEROUX C., VERDIÈRE R. 1989, «L'Attis de Catulle et son excès de haine contre Vénus », Paideia 44, p. 161-186. 
DETTMER H. 1997, Love by the Numbers: Form and Meaning in the Poetry of Catullus, Lang Classical Studies 10, New York.

DOMinicy M. 2001, « De l'anaclomène au galliambe », in J. Dangel (éd.), Le poète architecte : arts métriques et art poétique latin, Bibliothèque d'études classiques 24, Bruxelles - Paris - Sterling (Va.), p. 51-85.

DOMINICY M. 2002a, « Colométrie, période et rythme dans le lyrisme choral en Grèce ancienne », LEC 70, p. 321-352.

DOMinicy M. 2002b, « Une analyse poétique de Catulle 75 », in P. Defosse (éd.), Hommages à Carl Deroux. I, Poésie, Coll. Latomus 266, Bruxelles, p. 171-182.

DOMINICY M. 2005, « Colométrie et figures rimiques dans le lyrisme choral en Grèce ancienne », in M. Murat, J. Dangel (éds), Poétique de la rime, Métrique française et comparée 3, Paris, p. 55-73. Dominicy M. 2011, Poétique de l'évocation, Théorie de la littérature 3, Paris.

Dominicy M. 2012a, « De Catulle 113 à Properce IV, 11, 65-66 », Latomus 71, p. 392-403.

Dominicy M. 2012b, «L'adaptation des modèles grecs dans la versification latine : les indices d'une conscience métrique (Catulle 62 ; Horace, Carm. 2.18)», Interférences Ars scribendi 6 [en ligne].

DOMINICY M., NASTA M. 2009, « Towards a Universal Definition of the Caesura », in J.-L. Aroui, A. Arleo (éds), Towards a Typology of Poetic Forms: From Language to Metrics and Beyond, Language Faculty and Beyond 2, Amsterdam - Philadelphie, p. 247-266.

ÉVRARD-GILLIS J. 1976, La récurrence lexicale dans l'œuvre de Catulle : étude stylistique, Bibliothèque de la Faculté de philosophie et lettres de l'université de Liège 217, Paris.

ÉVRARD-GILLIS J. 1977, «Le jeu sur la personne grammaticale chez Catulle », Latomus 36, p. 114-122.

FANTUZZI M., HUNTER R. 2002, Muse e Modelli: la poesia ellenistica da Alessandro Magno ad Augusto, Collezione Storica, Rome.

FEDELI P. 1983, Catullus' Carmen 61, 2e éd., London Studies in Classical Philology 9, Amsterdam. FORDYCE C.J. 1973, Catullus: A Commentary, Oxford. FORSYTH P.Y. 1972-1973, « The Gellius Cycle of Catullus », CJ 68, p. 175-177. FORSYTH P.Y. 1978-1979, « Order and Meaning in Catullus », CW 72, p. 403-408. FORSYTH P.Y. 1992-1993, « The Fearful Symmetry of Catullus' Polymetrics », CW 86, p. 492-495. GIARDINA G.C. 1974, « La composizione del liber e l'itinerario poetico di Catullo: contributo alla sistemazione del problema », Philologus 118, p. 224-235.

GRANAROLO J. 1973-1974, « Catulle 1948-1973 », Lustrum 17, p. 27-70.

GRANAROLO J. 1982, Catulle, ce vivant, Collection d'études anciennes 150, Paris.

HOLZBERG N. 2002, Catull: der Dichter und sein erotisches Werk, Munich.

KORZENIEWSKI D. 1968, Griechische Metrik, Altertumswissenschaft, Darmstadt.

KOSTER W.J.W. 1962, Traité de métrique grecque ; suivi d'un Précis de métrique latine, $3^{\mathrm{e}}$ impr. corrigée, addenda, Leyde.

LOOMIS J.W. 1972, Studies in Catullan Verse: An Analysis of Word Types and Patterns in the Polymetra, Mnemosyne : bibliotheca classica Batava. Suppl. 24, Leyde. 
MARINONE N. 1997, Berenice da Callimaco a Catullo: testo critico, traduzione e commento, Testi e manuali per l'insegnamento universitario del latino 49 , Bologne.

MURAT M., DANGEL J. (éds) 2005, Poétique de la rime, Métrique française et comparée 3, Paris. NASTA M. 2001, Les êtres de paroles : herméneutiques du langage figuré, Cahiers de philosophie ancienne 17, Bruxelles.

NASTA M. 2002, « La relation mimétique et les anaphonies dans la poésie de Virgile », in P. Defosse (éd.), Hommages à Carl Deroux. I, Poésie, Coll. Latomus 266, Bruxelles, p. 385-397.

NASTA M. 2005, «La figure des vers 'éoliens' et le relief des homophonies : une préfiguration des réseaux de la rime ", in $\mathrm{M}$. Murat, J. Dangel (éds), Poétique de la rime, Métrique française et comparée 3, Paris, p. 11-53.

NASTA M. 2010, « Regards sur les degrés du processus mimétique », in D. Maci (éd.), Receptări ale filosofiei lui Platon și Aristotel în spațiul cultural românesc [= Réception de la philosophie de Platon et d'Aristote dans l'espace culturel roumain], Cluj, p. 7-43.

PUELMA M. 1995, Labor et Lima: kleine Schriften und Nachträge, Bâle.

QUIGNARD P. 1994, Le sexe et l'effroi, Paris, Gallimard.

QUINN K. 1959, The Catullan Revolution, Carlton [tirage revu : Cambridge].

QUINN K. 1972, Catullus: An Interpretation, Londres.

RUPPRECHT K. 1933, Griechische Metrik: eine Einführung, 2e éd., Munich.

SKUTSCH O. 1969, « Metrical Variations and Some Textual Problems in Catullus », BICS 16, p. 38-43. SYNDIKUS H.P. 1984, Catull: eine Interpretation. I, Einleitung. Die kleinen Gedichte (1-60), Impulse der Forschung 46, Darmstadt.

SYNDIKUS H.P. 1987, Catull: eine Interpretation. III, Die Epigramme (69-116), Impulse der Forschung 48, Darmstadt.

SYNDIKUS H.P. 1990, Catull: eine Interpretation. II, Die grossen Gedichte (61-68), Impulse der Forschung 55, Darmstadt.

TIMPANARO S. 1978, Contributi di filologia e di storia della lingua latina, Ricerche di Storia della Lingua Latina 13, Rome.

TRAPPES-LOMAX J.M. 2007, Catullus: A Textual Reappraisal, Swansea.

VAN SICKLE J.B. 1981, « Poetics of Opening and Closure in Meleager, Catullus and Gallus », CW 75, p. 65-75.

VEYNE P. 1983, L'élégie érotique romaine : l'amour, la poésie et l'Occident, Pierres vives, Paris.

WEST M.L. 1982, Greek Metre, Oxford.

WHEELER A.L. 1964, Catullus and the Traditions of Ancient Poetry, Sather Classical Lectures 9, Berkeley - Los Angeles.

WISEMAN T.P. 1976, « Catullus $16 »$, LCM 1, p. 14-17.

WISEMAN T.P. 1979, Clio's Cosmetics: Three Studies in Greco-Roman Literature, Leicester.

WILKINSON L.P. 1956, in J. Bayet, A. Rostagni, V. Pöschl et al., L'influence grecque sur la poésie latine de Catulle à Ovide : six exposés et discussions, Vandouvres - Genève, 2-7 août 1953, Entretiens sur l'Antiquité Classique 2, Vandœuvres - Genève, p. 47-68. 
WILKINSON L.P. 1974, «Catullus LI again », G\&R 21, p. 83-85.

\section{NOTES}

1. Cf. Bardon 1970, chap. vI, p. 75-87 : «Le "moi” et les "Autres" ».

2. Cette ambiance devient parfaitement visible dans le Pro Archia de Cicéron (daté de 62 av. J.-C.). La plaidoirie défend la cause d'un poète grec, reçu avec faveur dans la plus haute société romaine, mais dont il fallait assurer la 'naturalisation' pour le défendre contre les menées d'un adversaire malveillant (et obscur), Grattius, qui l'accusait de ne pas posséder le droit de cité romaine.

3. Un écho se répercute chez Virgile, à l'instar des emblèmes qui annoncent l'usage d'une tradition poétique venue d'ailleurs et le charme de ses 'chants' versifiés - cf. Ecl. 4, 1 <l'incipit> : Sicelides Musae... et Ecl. 6, 1-2 : Prima Syracosio dignata est ludere versu / Nostra ... Thalia.

4. Dans quelques ouvrages d'érudition perdus, les grammairiens citaient de surcroît l'apport d'un esclave hellène acclimaté, Parthénius de Nicée. Versificateur habile, arrivé sur le sol italique vers 73 av. J.-C., il aurait aidé avec compétence les poètes Cornelius Gallus et Helvius Cinna dans leurs tentatives d'adaptation des formes élégiaques et du propemptikon - cf. la Souda, s.v.

5. Voir, particulièrement, Horace, Ep. 2, 2, 100, et le contexte de cette mention. Quant aux travaux des historiens littéraires qui traitent des influences grecques, on a l'embarras du choix, depuis les synthèses de Wilkinson 1956, Syndikus 1987 et Fantuzzi, Hunter 2002, jusqu'à Wiseman 1979, Quinn 1959 et 1972, Van Sickle 1981, Puelma 1995, Holzberg 2002 (notamment p. 40 sq.), Bellandi 2007 (passim). J'insiste avec priorité sur les aspects particuliers des empreintes reprises aux épigrammes hellénistiques dans la perspective de l'intertextualité. Celle-ci prévaut sur les autres mimétismes catulliens, surtout dans la deuxième section du 'recueil'. À partir des carmina 65-66, jusqu'à la dernière pièce (Catul.116), tout est versifié en distiques élégiaques et la moulure d'encadrement du carmen 66 décalque par des transferts interlinguistiques partiels un poème corrélatif de Callimaque (fr. 110, 1 sq. Pfeiffer); rapports analysés en détail par Marinone 1993. Nos observations préciseront dans ce qui suit les rapports mimétiques et les incidences du 'vécu' inhérentes aux factures mixtes ou issues d'une diffraction de l'expérience individuelle.

6. Cf. Cicéron, Tusc. 3, 19, 45, qui parle du mépris de ces cantores Euphorionis à l'égard de la rudesse d'un Ennius. Voir également dans Cic., ad Att. 8, 5, 1, le vers grec cité d'Euphorion, qui correspond exactement au vers 111 du carmen 64 de Catulle (tout comme, dans cette même composition, l'interrogation rhétorique du vers 30). Pareillement, le vers 96 (Quaeque regis Golgos quaeque Idalium frondosum) est habilement adapté d'une gracieuse invocation chantée par une femmeaède officiant aux fêtes d'Adonis (Theocr. 15, 100).

7. Cf. Veyne 1983, p. 41-146.

8. Voir dans Veyne 1983, chap. v : «La mauvaise société » (p. 78-96 et 105 sq.) et la présentation de Properce comme éditeur d'ego (p. 105 sq.). Mais qu'advient-il dans ce réquisitoire de la Vénus de Lucrèce?

9. Quand il s'essayait dans le domaine de la poésie philosophique, Cicéron adaptait sagement Aratos et dans cette nouvelle entreprise il devait en premier lieu surmonter des difficultés de toutes sortes pour traduire le vocabulaire de l'énonciation descriptive scientifique.

10. J'attire l'attention sur les vertus du langage de l'historien propagandiste: la tenue 'normative' du delectus uerborum et la syntaxe de César dans le Bellum Gallicum sont d'une belle prestance. La rigueur d'un 'analogiste' et son effort personnel pour contenir le déploiement phrastique se démarquent du style bien plus hésitant de son continuateur (et adjoint) qui a rédigé le Bellum civile ou le Bellum Africum. 
11. Voir encore Bardon 1970, p. 63-128: Le «moi » et le «tu», section dont je retiens surtout les chapitres v («L'obscénité »), VII (« Le “moi” et le mythe ») et IX (« La solitude »).

12. Cette assertion pathétique revient plusieurs fois avec emphase dans le premier libellus : ainsi dans le carmen 37, 11-12 (Puella nam mi, quae meo sinu fugit, / amata tantum quantum amabitur nulla), sans compter les variations qui ont transformé ce même thème.

13. Cf. Claes 2002, chap. II, p. 27-56 et passim. Ce principe de concaténation ou d' "enchaînement » circulaire se vérifie progressivement, depuis le plan thématique ( $\mathrm{TC}=$ repetition of similar themes or motifs) jusqu'aux niveaux des signifiants concrets: itérations du vocabulaire (LC = lexical concatenation) et récurrences phonémiques. Le procédé et le terme de concaténation furent déjà définis par Beauzée au XVIII ${ }^{\mathrm{e}}$ siècle pour désigner la gradation « où un mot se répète d'un membre dans le membre suivant et les enchaîne ainsi les uns aux autres ». Cf. esp. concatenación : "figura que se comete empleando al principio de dos o más cláusulas o miembros del período la ultima voz del miembro o cláusula inmediatamente anterior ». La tension du climax et les morsures de l'ironie s'ajoutent presque chaque fois chez Catulle aux effets produits par ce maniement des paroles.

14. À retenir pareillement la définition lexicologique d'un emploi spécifique de l'incastro italien : "jeu qui consiste à introduire une ou plusieurs syllabes dans un mot, pour obtenir un autre vocable ». Ainsi dans seta, "soie », on peut insérer les syllabes re-na pour obtenir serenata, "la sérénade ». Dans Catul. 112, on a dépisté une difficulté qu'on arriverait à surmonter par ce jeu de syllabes. Le syntagme à incastro /1/ Naso neque tecum \{multus-homo-est\} qui /2/ descendit / contient un calembour qui achève le distique: /Naso, \{multus-es\} pathicus!'/. Le multus du vers 2 est un adjectif à connotation lubrique : «moulu », donc pathicus. Voir la note a.l. dans l'édition de la CUF et le commentaire critique de Thomson 1997, p. 549-550.

15. Cf. Dettmer 1997. Voir également (pour les récurrences lexicales) Évrard-Gillis 1976 et 1977. Parmi les vers d'encadrement qui ouvrent et clôturent le poème (Klammertechnik), signalons la répétition des appels injurieux, les menaces, les interrogations de l'ego, les imprécations : Annales Volusi, cacata charta /... (Catul. 36, 1 et 20). Voir encore Pedicabo ego uos... (Catul. 16, 1 et 14) et le pathétique Quid est, Catulle? quid moraris emori ? (Catul. 52, 1 et 4) ou moecha putida redde codicillos, ordre menaçant, réitéré avec des variantes (Catul. 42, 11-12, 19-20), etc.

16. Pour d'autres occurrences de ce thème, voir Catul. $45,12$.

17. Les manuscrits donnent ici 'solet esse ymaginosum'. La charge inclut une comparaison redoutable avec les gracieuses proportions de Lesbie. L'ingénieuse correction nec rogare / qualis sit solet aes imaginosum ! / [ « «ec rogare solet aes imaginosum qualis sit "] s'avère excellente. Aes désignerait un miroir en bronze. La coquette «ne s'est pas habituée à demander au bronze qui renvoie son image quelle serait <sa véritable apparence> ».

18. À l'égal des modalités différentes mises en exergue chez Virgile, dès les premiers abords d'une lecture grammairienne, qui louait la facture prédominante des genres et les styles distincts, inhérents aux trois types de poèmes (Eclogae, Georgicon, Aeneis), salués par la célèbre formule emblématique de l'épitaphe, qui aurait pu provenir d'un hommage posthume du scoliaste : cecini pascua, rura, duces.

19. Cf. Fedeli 1983.

20. Voir un aperçu équilibré des différentes positions dans Holzberg 2002, p.11-60 : 'À la recherche de l'auteur caché'.

21. On n'a pas hésité à incriminer, à la suite de Birt, la séquence chaotique des pulsions qui se font jour au fil des carmina. Des avis divergents chez Wheeler 1964, Giardina 1974 et Van Sickle 1980.

22. Cf. Catul. 1, 8-9: Quare habe tibi quiquid hoc libelli, / Qualecumque...

23. Pour le traitement de la 'base' initiale, voir Dominicy $2012 b$.

24. Le modèle générique des iambi d'agression, comme celui des épodes, datait d'Archiloque, d'Hipponax et de Sémonide d'Amorgos, cf. Hor., Ep. I, 19, 23-29. Callimaque avait aussi composé un recueil de Iambes, hétérogène. 
25. Voir également Dominicy $2012 b$.

26. Voir supra.

27. Parcours d'autant plus visible pour un public friand d'aventures sentimentales si on le rapporte aux 'intrigues' amoureuses des premiers romans de l'Antiquité, versifiés ou transmis comme des récits en prose (contes milésiens, mythopoèmes légendaires, etc.).

28. Voir Veyne 1983, chap. VIII : « Nature et usage de la mythologie », p. 130-146.

29. Dès le vers 6 : consurgite contra ; / nimirum Oetaeos ostendit Noctifer ignes ; 32 sq. : Hesperus e nobis, aequalis, abstulit unam <...> / nocte latent fures, quos idem saepe reuertens, / Hespere mutato comprendis nomine Eous.

30. Cf. Barbaud 2006, chap. III 1, p. 192-195 : «Ressources itératives : les poèmes 61, 62 et 63 ». À retenir, dans ce contexte, une définition appropriée des itérations expressives chez Catulle: «les répétitions constituent (pour la valorisation du thème) ce que l'on peut nommer une boucle ou complexio, si bien que les vers légèrement altérés par la variation (ou par la 'modulation récursive') s'infléchissent et peuvent donner la tonalité d'une chanson (ex. 3, 3-4: passer mortus est <...> / passer deliciae meae puellae) ou le brio d'une ritournelle qui fait danser les chiffres (comme dans 5, 7-9: da mi basia mille, deinde centum / dein... mille... centum / deinde... mille centum) ou bien, comme dans le cas du refrain que nous discutons ci-dessus. Les cadences de tout un vers (parfois celle d'un couplage stichique) résonnent solennelles, pour assurer l'accomplissement fatidique d'une action <instanciée>, lors de l'assertion qui se répète ».

31. Voir l'excellente synthèse de Deroux, Verdière 1989, p. 163 sq. Pour le galliambe, cf. Dominicy 2001, p. 51-85.

32. La métaphore du «joli petit livre» offert au destinataire dans le poème introductif s'accompagne d'une prière à la 'patronne' divine (Minerve ou l'une des Muses). Et ceci témoigne du nouveau parcours alexandrin de la dédicace-invocation, qui doit lancer un périple de lecture dans un monde urbain qui s'accoutumait déjà aux prestiges de l'écriture. Aux dernières escales du Moyen Âge littéraire européen, on découvrira le topos de la nef, qui doit s'élancer faustis ventis spirantibus... chez Dante : la «navicella del ingegno » (Purgatoire I, 1-5). L'image métaphorique du «livre» de poèmes, auquel un poète confie son message introductif pour se concilier des lecteurs, acquiert un relief pathétique chez Ovide (voir, par ex., dans Trist. 1, 1, le très long discours de recommandations, dont l'image du début se ressent de l'influence catullienne).

33. Voir les remarques de Bardon 1970, chap. $x$, p. 131-140: «La construction du MOI par la poésie ».

34. Des treize pièces où Lesbie est évoquée nommément, cinq seulement font partie du libellus. Après la terrible déprécation de Catul. 58 (spirale de trois exclamations!), dans le reste du 'recueil' le nom apparaît encore huit fois. L'emphase de 87, 1-4, n'est qu'une variatio habilement tressée, qui reprend les termes du poème 58 , où Lesbie n'est pas nommée. Ailleurs, la simple mention métaphorique de ce thème devient tout aussi expressive que le nom (voir, ci-dessus, le commentaire de Catul. 11).

35. Beaucoup ont préféré s'attarder sur la 'subjectivité' des assertions lyriques du poète. Or il faut se garder de lui prêter la sensibilité maladive d'un romantique. Les cris de rage et l'indignation préparent chez lui une réaction lucide qui lui enjoint de se ressaisir ou de noircir l'amante infidèle.

36. Voir le texte dans A.P., Livre VII (CUF, t.V, ép.476, p.59). Parmi les loci paralleli, le commentaire de Kroll (a.l.) cite encore l'image virgilienne de la mort d'Euryale (Verg., Aen. IX, 435-437).

37. À la limite, j'oserais même parler d'un dessein d'auteur qui voudrait nous représenter dans ce genre de poèmes une 'optique en contre-plongée' de ses amours.

38. La discussion des propriétés significatives qui fondent l'opposition poiéseis // poemata se profilait déjà chez Néoptolème et dans les traités de Philodème (cf. Neubecker [ed.] 1986, p. 20 sq., et surtout Mangoni [ed.] 1993). 
39. Le scénario de l'Hyménée dans Catul. 62 a été tourné dans un moule distinct, par rapport à l'É pithalame du carmen 61.

40. Il faudrait encore différencier les épigrammes des inserts ou des poèmes et 'tableaux de genre', plaqués dans un autre poème, comme dans Catul. 64, les péripéties d'Ariane, récit tiré d'un peplum - toile historiée (voir supra).

41. Chez le Véronais lui-même, ce thème du pavot fauché quand la fleur 's'éveillait' à peine s'entrelace également avec la trace de plusieurs symboles apparentés du bonheur éphémère : la fuite d'Atalante, le destin de Laodamie ou la thématique du rapt et de l'appariement, à propos d'Ariane et de la chaste vierge qui apparaît dans une comparaison de l'Hyménée : Ut flos in saeptis secretus nascitur hortis..., etc. (Catul. 63, 39-45).

42. Cf. Bellandi 2007, chap. II.4 : «La poetica del lepos». L'auteur définit avec bonheur l'originalité de l'understatement qui sous-tend cette modalité. Ensuite, p. 51, à propos de l'implication du lecteur: "dell'elemento pathos a livello autoriale si può tacere <essendo> inprogrammabile ed ineffabile. Lo si può/deve constatare à priori da parte del lettore. Chi usufruiisce per lettura o audizione della poesia può ricavarne effetti di pathos, anche paradossalmente, come nel caso del c. 50 : "Hesterno Licini / multum lusimus in meis tabellis..." " 43. Carmen 87, dont nous donnons ci-dessus la version fragmentaire d'une sentence de clôture, désemparée.

44. Sur un ton grave, à peine ironique, voir également cet envoi à l'ami Calvus : Hoc, iocunde, tibi poema feci, / Ex quo perspiceres meum dolorem... / Nunc audax caue sis precesque nostra. / Oramus : caue despuas ocelle / Ne poenas Nemesis reposcat a te (Catul. 50, 16-20).

45. Cf. Quignard 1994, p. 77 sq.

46. Voir Catul. 5, 2 : rumoresque senum seueriorum. Et, plus loin, v. 12 : ne quis malus inuidere possit.

47. Mentionné à trois reprises - 36, 1, 22 ; 95, 7 - et identifié dans Sen., Ep. 93.

48. La fiction de l'encadrement du «livre» ou d'un envoi pourrait être sous-entendue à maintes reprises : ainsi, par antiphrase, dans le poème à Calvus (Catul.14) et diversement ailleurs comme dans $35,46,75,92,107$.

49. Cf. Timpanaro 1978, p. 177.

50. Voir la notice de Thomson 1997, p. 554-555. Le 'cycle' de Gellius comprend en outre les épigrammes 74,80 , 88-91.

\section{RÉSUMÉS}

L'article propose une mise au point des problèmes qui ont trait à l'énonciation des thèmes et aux enjeux de l'expression littéraire chez Catulle, en analysant l'oscillation entre déploiement de procédés spécifiques aux poetae noui et expression d'un ego marqué par une troublante spontanéité. La réflexion envisage en particulier dans ce contexte la structure du recueil catullien. 


\section{INDEX}

nomsmotscles Archiloque, Caecilius Statius, Callimaque, Catulle, César, Cicéron, Cornificius, Ennius, Euphorion, Helvius Cinna, Hipponax, Horace, Hortensius Hortalus, Licinius Calvus, Lucilius (Caius), Martial, Naevius, Parthénios de Nicée, Properce, Salluste, Sappho, Théocrite, Valerius Cato, Virgile

Index géographique : Asie Mineure, Grande-Bretagne, Sicile

Keywords : biography, metric awareness, concatenatio Catulliana, Greek and Latin metric, ethics and literature, scholarship, poetae noui, hellenism, literary awareness, literariness, literary sociology, alexandrinism, mixed genres, collections of poems, metaliterary discourse, poetic tradition

Mots-clés : biographie, conscience littéraire, conscience métrique, critique universitaire, discours métalittéraire, littérarité, métrique gréco-latine, morale et littérature, tradition poétique, poetae noui, hellénisme, sociologie littéraire, alexandrinisme, concatenatio Catulliana, mélange des genres, recueil

\section{AUTEURS}

\section{MIHAÏL NASTA}

Université libre de Bruxelles et Université Babeș-Bolyai (Cluj) 